\title{
Elementary School Teachers' Growth Mindsets Predict Their Differential Treatment of High Versus Low Ability Students
}

\author{
David B. Miele ${ }^{1}$, Shenira A. Perez ${ }^{1}$, Ruth Butler ${ }^{2}$, Alexander S. Browman ${ }^{1}$, \\ Laura M. O’Dwyer ${ }^{3}$, and Daniel McNeish ${ }^{4}$ \\ ${ }^{1}$ Department of Counseling, Developmental, and Educational Psychology, Boston College, \\ 309 Campion Hall, 140 Commonwealth Ave., Chestnut Hill, MA 02467, USA; \\ d.miele@bc.edu,perezsj@bc.edu, browman@bc.edu \\ ${ }^{2}$ School of Education, Hebrew University of Jerusalem, Jerusalem, Israel; \\ ruth.butler@mail.huji.ac.il \\ ${ }^{3}$ Department of Measurement, Evaluation, Statistics, and Assessment, Boston College, 339 \\ Campion Hall, 140 Commonwealth Ave., Chestnut Hill, MA 02467, USA; \\ laura.odwyer@bc.edu \\ ${ }^{4}$ Department of Psychology, Arizona State University, 1503 E University Blvd., Building \\ 68, Tucson, AZ 85721,USA; dmcneish@asu.edu
}

Author Note

This research was supported by funding from the Buehler Sesquicentennial Assistant Professorship and from Collaborative Grant No. 220020483 from the James S. McDonnell Foundation. We thank Marina Vasilyeva for her comments on an earlier draft of this paper. We also thank Sidney May and Meghan Coughlan for their help in preparing the manuscript.

Correspondence concerning this article should be addressed to David B. Miele, Department of Counseling, Developmental, and Educational Psychology, Boston College, Chestnut Hill, MA 02467. Email: d.miele@bc.edu 


\begin{abstract}
We examined the relation between teachers' beliefs about the nature of intelligence (their growth mindsets) and their treatment of high versus low ability students. Two studies were conducted: one with undergraduates $(N=174)$ who imagined working with fictional students, and one with in-service elementary school teachers $(N=245)$. Across studies, participants with weaker growth mindsets reported being more likely to use performance-oriented practices and less likely to use mastery-oriented practices with students they perceived to be low (rather than high) in ability. Participants with stronger growth mindsets reported this kind of differential treatment to a significantly lesser extent.
\end{abstract}

Keywords: growth mindsets, teacher beliefs, instructional practices, differential treatment, student ability. 


\section{Elementary School Teachers' Growth Mindsets Predict Their Differential Treatment of High Versus Low Ability Students}

Some teachers engage in instructional practices that promote students' sense of autonomy and encourage them to master the class content. Such practices have repeatedly been linked to positive student outcomes, such as increased academic engagement, greater conceptual understanding in math, and higher course grades (Jang, Reeve, Ryan, \& Kim, 2009; Niemiec \& Ryan, 2009; Reeve, Jang, Carrell, Jeon, \& Barch, 2004; Renkl \& Helmke, 1992; Stipek, Givvin, Salmon, \& MacGyvers, 2001). Other teachers tend to rely more on practices that make students feel controlled and concerned with outperforming their peers. These practices have been shown to undermine students' intrinsic motivation, their preference for challenging tasks, their growth mindsets regarding intelligence, and their performance on problems requiring analytical reasoning (Boggiano, Flink, Shields, Seelbach, \& Barrett, 1993; Park, Gunderson, Tsukayama, Levine, \& Beilock, 2016; Soenens \& Vansteenkiste, 2005).

Because the types of practices that teachers utilize have implications for a variety of student outcomes, it is important to identify individual difference factors that help explain why some teachers prefer one type of practice over another. One such factor is teachers' beliefs about the nature of intellectual ability, also known as their academic mindsets (Dweck \& Molden, 2017). Several studies have shown that compared to teachers who believe that intelligence is malleable (i.e., those who have a growth mindset), teachers who believe that intelligence is fixed (i.e., those who have a fixed mindset) are more likely to rely on performance-oriented and controlling instructional practices (Jonsson \& Beach, 2012; Leroy, Bressoux, Sarrazin, \& Trouilloud, 2007; Park et al., 2016; Stipek et al., 2001). 
In general, these studies have tended to examine how teachers' mindsets affect the classroom practices they engage in with all students. However, teachers sometimes differentiate their instruction based on perceptions of individual students' abilities (see Babad, 1993, for a review). As a result, there is reason to expect that teachers' mindsets might also influence the extent to which to they engage in certain practices when interacting with students they perceive to be high versus low in ability. This is an important topic because differential treatment can adversely affect the academic performance and self-confidence of students who are perceived to be low in ability (Babad, 1993; Jussim, Robustelli, \& Cain, 2009). Thus, in two studies, we investigated the relation between teachers' growth mindsets and the instructional practices they use with high versus low ability students.

\section{Categories of Instructional Practices}

One element that characterizes teachers' instruction is the extent to which they rely on autonomy-supportive versus controlling practices (Ryan \& Deci, 2016). Autonomy-supportive practices involve tailoring material to students' interests, encouraging them to play an active role in their learning, and providing them with opportunities to become increasingly independent in their learning (Reeve, 2012; Reeve \& Jang, 2006). In contrast, controlling practices restrict students' autonomy and rely on methods of external regulation in order to engage students. Examples of such practices include pressuring students to think and act in specific ways, limiting their participation during lessons, and using rewards/punishments to manage their motivation (Good \& Brophy, 1974; Sarrazin, Tessier, Pelletier, Trouilloud, Chanal, 2006). Prior research shows that a broad range of academic outcomes are positively associated with teachers' use of autonomy-supportive practices and negatively associated with their use of controlling practices 
(Black \& Deci, 2000; Boggiano et al., 1993; Grolnick \& Ryan, 1987; Hardre \& Reeve, 2003; Stronge, Ward, \& Grant, 2011).

Another important dimension of instruction is the extent to which teachers' practices emphasize the goal of attaining mastery in a domain versus outperforming one's peers. Masteryoriented practices, such as praising students for their hard work, encourage students to develop a deep understanding of the material and to focus on their progress over time (Patrick, Anderman, Ryan, Edelin, \& Midgley, 2001; Retelsdorf, Butler, Streblow, \& Schiefele, 2010). In contrast, performance-oriented practices, such as publically praising students for receiving high test scores, encourage students to learn only what they need to know in order to earn good grades and to focus on how they compare to others (Dweck \& Leggett, 1988; Park et al., 2016; Patrick et al., 2001; Stipek et al., 2001). As with the previous dimension, research suggests that important student outcomes are positively associated with mastery-oriented instructional practices and negatively associated with performance-oriented practices (see Meece, Anderman, \& Anderman, 2006).

Although a clear theoretical distinction can be made between the autonomysupportive/controlling dimension of instruction and the mastery/performance-oriented dimension, these constructs may converge in certain contexts. For example, a factor analysis of elementary school teachers' practices showed that teachers' use of mastery-oriented practices and autonomy-supportive practices loaded onto one factor, whereas their use of performanceoriented practices loaded onto another (Stipek et al., 1998; see also Moorman \& Pomerantz, 2010). Thus, the current study examined the two dimensions of instruction as a single construct, contrasting teachers' use of mastery-oriented and autonomy-supportive practices (hereafter 
referred to as mastery-oriented practices for short) with their use of performance-oriented and controlling practices (referred to as performance-oriented practices).

\section{The Relation Between Teachers' Academic Mindsets and Instructional Practices}

One factor that has been shown to influence teachers' use of mastery- versus performance oriented instructional practices is their academic mindsets. For instance, Stipek and colleagues (2001) conducted a study in which they assessed sixth-grade teachers' self-reported beliefs about mathematics teaching and observed their practices during math lessons. The authors found that teachers' fixed mindsets regarding math ability were significantly positively associated with their use of performance-oriented practices, but marginally negatively associated with their provision of autonomy and their emphasis on conceptual understanding (see Leroy et al., 2007, and Park et al., 2016, for similar findings).

One potential explanation for such findings is that teachers with fixed mindsets are more likely than teachers with growth mindsets to conclude that students who are struggling to complete a challenging task have reached the limits of their ability in that domain (see Dweck, 1999), and thus there is not much that they as teachers can do to help these students improve their ability. This conclusion may lead them to engage in performance-oriented behaviors aimed at ensuring that their students at least meet the minimum performance standards of the class. Indeed, concerns about meeting performance standards can lead teachers to engage in performance-oriented practices (Deci, Spiegel, Ryan, Koestner, \& Kauffman, 1982; Flink, Boggiano, \& Barrett, 1990), and such concerns may be especially salient among teachers who do not believe that struggling students' abilities can be improved. Conversely, teachers with growth mindsets may be more likely to interpret struggle as instrumental for developing new skills (i.e., mastery). This interpretation may lead them to engage in mastery-oriented behaviors that foster 
intellectual growth even when initial performance is poor (i.e., when student ability is perceived as being low).

\section{Differential Treatment of Students}

The studies cited in the previous section provide evidence of a relation between teachers' mindsets and their general use of mastery- versus performance-oriented practices. However, research has shown that teachers may also differentiate their instruction based on their perceptions of individual students' abilities. Specifically, this literature has shown that teachers may more inclined to engage in supportive practices with students they perceived as being high in academic ability (or potential) than with students they perceived as being low in ability. For instance, Babad, Inbar, and Rosenthal (1982) found that, overall, physical education teachers were more supportive and less controlling towards students for whom they had high (versus low) expectations. This was true regardless of whether teachers' expectations were based on experience or were induced by experimenters and unrelated to students' actual abilities (see also Brophy \& Good, 1970). Such patterns of differential treatment are important because they can ultimately produce or exacerbate differences in actual ability; that is, they can lead to expectancy effects (e.g., Brattesani, Weinstein, \& Marshall, 1984; Kuklinski \& Weinstein, 2001).

The Present Research: The Relation Between Teachers' Academic Mindsets and Differential Treatment

The present paper aims to connect the teacher mindset literature with the literature on teachers' differential treatment of low versus high ability students. As discussed, teachers with fixed mindsets may be more likely than those with growth mindsets to engage in performanceoriented behaviors when interacting with a struggling student because they are likely to infer that the student has reached the limits of his or her ability (see Dweck, 1999). However, these 
teachers may be especially likely infer this when they perceive the student as lacking innate ability in that domain. By contrast, when they believe that the student's ability is high, the same teachers may instead interpret any setbacks as mere bumps in the road toward mastery.

Consistent with this possibility, one might expect teachers with fixed mindsets to be more likely than teachers with growth mindsets to report using performance-oriented practices (and less likely to report using mastery-oriented practices) with students that they perceive as being low in ability. In contrast, the two groups of teachers might be equally likely to engage in these practices with students they perceive as being high in ability. Relatedly, one might also expect teachers with fixed mindsets to engage more in performance-oriented practices (and less in mastery-oriented practices) with low ability students than with high ability students, whereas teachers with growth mindsets might be equally unlikely to engage in performance-oriented practices with these two groups. That is, teachers with fixed mindsets might be more likely than teachers with growth mindsets to differentiate their treatment of high and low ability students.

To the best of our knowledge, only one study has investigated these ideas. Specifically, Lee (1996) presented a sample of Korean elementary school teachers with information related to a hypothetical student's performance on an academic task and then asked them to provide feedback. Consistent with the previously reviewed studies, teachers with fixed mindsets were more likely than those with growth mindsets to provide ability-oriented (vs. effort-oriented) feedback, give performance-oriented (vs. mastery-oriented) reasons for selecting a follow-up assignment, and recommend placement into an ability-heterogeneous group. In addition, teachers with fixed mindsets were more likely to differentiate their treatment of students based on perceived ability level: teachers with fixed (versus growth) mindsets were more likely to give performance-oriented reasons for their assignment selection when they perceived the student as 
having low (vs. intermediate) ability. While these results are consistent with our expectations, Lee (1996) found that participants with fixed mindsets were also likely to give performanceoriented reasons when they perceived the student as having high (vs. intermediate) ability. This surprising result may have been due to methodological limitations of the study. Most notably, because teachers self-reported their perceptions of the hypothetical student's ability, some comparisons were based on cells that contained very few participants. In particular, only 18 of the 200 teachers in the sample perceived the student as being high in ability.

\section{Overview of the Present Studies}

We conducted two studies to examine the relation between teachers' mindsets and their differential treatment of students with low versus high levels of academic ability. In both studies, participants read a series of scenarios in which a student was described as struggling to complete a school assignment. For each scenario, participants rated how likely they would be to use different instructional practices when working with the student. Some of the students were identified as being above average or having high ability in a particular domain, while others were identified as being below average or having low ability. In Study 1, which included a sample of undergraduate students enrolled in an education school course, the scenarios described fictional students. In Study 2, which included a sample of in-service elementary school teachers, participants were asked to think about students whom they were currently working with or who they had worked with in the past, who were either low or high in ability. By specifying the ability level of the student in each scenario (rather than measuring participants' perceptions of the student's ability) we avoided the methodological limitation of Lee's (1996) study.

\section{Study 1}

\section{Method}


Participants. Our study was completed by 186 undergraduate students enrolled in an education school course at a private university in the Northeastern United States. They were primarily first year students going on to major in Elementary Education, Secondary Education, or Applied Psychology. The data of 12 participants were excluded because either they did not finish the study $(\mathrm{N}=2)$, they were missing one or two responses for the domain-specific mindset measures $(N=9)$, or they exhibited no variability in their responses $(N=1) .{ }^{1}$ A final sample of 174 participants was therefore retained in our analyses $\left(86.2 \% ; M_{\mathrm{age}}=18.94, S D=1.18 ; 75.1 \%\right.$ White, 13.9\% Asian/Asian-American, 4.0\% Hispanic/Latinx, 2.9\% Black, 3.5\% Multi-racial, and $.6 \%$ Native-American). One participant did not indicate race/ethnicity.

\section{Materials.}

Instructional practices. Participants were presented with eight scenarios in which they were instructed to imagine that they were teaching a $4^{\text {th }}$ grade class of 23 students and that one of the students was struggling to complete the task assigned for that class period. Four of the scenarios involved the fourth graders completing a math assignment and four involved them completing a language arts assignment. We varied the domain of the scenarios in order to investigate whether the hypothesized effects would generalize to multiple academic contexts. Within each domain, two of the scenarios described a student who was above average in that domain and two described a student who was below average. The two above average (i.e., high performing) math students were described as struggling with either a fractions or geometry assignment, whereas the two below average math students (i.e., low performing) struggled with a word problem or measurement assignment. In contrast, the two above average language arts

\footnotetext{
${ }^{1}$ The exclusions criteria were developed when the construct of domain-specific mindsets (now reported in the supplementary materials) was more a central construct. For more details about the exclusion criteria and the sequence of analyses, see the supplementary materials.
} 
students were described as struggling with either a grammar or vocabulary assignment, whereas the two below average language arts students struggled with an analogy or reading comprehension assignment. We varied assignment type across the eight scenarios in each domain in order to make the task seem less tedious to participants. The scenarios were divided into two blocks of four scenarios, each containing one high ability scenario and one low ability scenario for each domain (i.e., verbal and math). The scenarios order in each block was randomized across participants. All of the students described in the scenarios had traditionally female names, as the vast majority of the participants in the study were female.

Following each scenario, participants were asked how likely they would be to use each of ten different "strategies" for helping the student successfully complete the assignment. These strategies (i.e., instructional practices) were adapted from prior research (Bohlmann \& Weinstein, 2013; De Meyer et al., 2014; Doabler et al., 2014; Good \& Brophy, 1974; Leroy et al., 2007; Muenks, Miele, Ramani, Stapleton, \& Rowe, 2015; Munro, 1999; Patall, Dent, Oyer, \& Wynn, 2013; Rattan, Good, \& Dweck, 2012; Reeve \& Jang, 2006; Sarrazin et al., 2006; Shim, Cho, \& Cassady, 2013; Tomic, 1989) and presented in a random order. Five of the items assessed mastery-oriented or autonomy-supportive instructional practices (e.g. "Provide her with hints about how to solve the problem she is struggling with without actually solving the problems for her") and the other five assessed performance-oriented or controlling instructional practices ("Give her the solutions to the problems she is struggling with"; see the supplementary materials for a full list of items). Note that, in contrast to some existing scales for measuring mastery-oriented and performance-oriented instructional practices (such as the Approaches to Instruction subscales from the PALS; Midgley et al., 2000), our scale assesses specific practices for interacting with particular students rather than general classroom behaviors. 
Participants were asked to rate the likelihood (on a 6-point scale from "Very Unlikely" to "Very Likely") that they would employ each "strategy" in order to help the struggling student depicted in each scenario successfully complete the assignment. Indices were created by first computing the mean of the five items in each subscale for each scenario (performance-oriented: $M \mathrm{~s}=1.98-2.58, S D \mathrm{~s}=.67-.86, \alpha \mathrm{s}=.54-.64$, mean $\alpha=.57, \omega_{\text {ordinal }}=.68-.77$, mean $\omega_{\text {ordinal }}=.72 ;$ mastery-oriented: $M \mathrm{~s}=4.82-5.06, S D \mathrm{~s}=.54-.67, \alpha \mathrm{s}=.41-.56$, mean $\alpha=.49, \omega_{\text {ordinal }}=.59-.74$, mean $\left.\omega_{\text {ordinal }}=.65\right) .{ }^{2}$ These means were then averaged across the two scenarios in each domain $\times$ ability level condition to create four performance-oriented indices and four mastery-oriented indices. See the supplementary analyses for exploratory factor analyses (EFAs) of the scale; and note that the scale was revised in Study 2 to improve the clarity and reliability of the items.

Academic mindsets. Academic mindsets were measured with the 8-item version of Dweck's (1999) implicit theories of intelligence scale - the most highly validated and frequently used measure of academic mindsets (see Burnette, O`Boyle, VanEpps, Pollack, \& Finkel, 2013). The scale consists of 4 items assessing a fixed mindset (e.g. "To be honest, you can't really change how intelligent you are") and 4 items assessing a growth mindset (e.g. "You can change even your basic intelligence level considerably"); they were presented in a single mixed order. Participants were asked to indicate the extent to which they agreed with each item on a 1 (“Strongly Disagree”) to 6 (“Strongly Agree”) scale. Participants' mindset scores were computed by reverse-coding the 4 fixed items, computing the mean for each participant across all 8 items, and then standardizing the resulting variable such that the index was centered at the mean $(M=$

\footnotetext{
${ }^{2}$ For several reasons (detailed in the supplementary materials), the Cronbach's alpha $(\alpha)$ coefficients were likely an underestimate of the internal consistency reliability of our measure. Thus, we also report omega as a measure of reliability (see Dunn, Baguley, \& Brunsden, 2014; McNeish, 2018). Note that we computed an ordinal version of omega ( $\left.\omega_{\text {ordinal }}\right)$ based on polychoric correlations in order to account for strong skew of the ordinal Likert-type items (Gadermann, Guhn, \& Zumbo, 2012; cf. Chalmers, 2018). See the supplementary materials for more details.
} 
4.23, $\left.S D=.88, \alpha=.92, \omega_{\text {ordinal }}=.94\right)$. Thus, the higher the score on this index, the more of a growth mindset (and the less of a fixed mindset) participants exhibited. It is worth noting that the mean in this study was significantly higher than the midpoint of the scale, $t(173)=10.99, p<$ .001 , reflecting the fact that $81 \%$ of participants reported scores that were indicative of a growth mindset (i.e., higher than the midpoint of the scale at 3.5). Therefore, the results of our primary analyses are framed in terms of differences between teachers with relatively strong versus weak growth mindsets.

Procedure. The study was administered on desktop computers in the laboratory using Qualtrics Research Suite. Participants initially completed a task that pertained to a related but distinct set of hypotheses not discussed in this paper ${ }^{3}$, and then responded to the eight scenarios. Next, they completed the general academic mindset scale. In addition, we included a domainand child-specific mindset measure, which is described in the supplementary materials. For the sake of brevity, we focus on the general mindset measure because (unlike the domain-specific measure) it yielded a consistent association with differential treatment across both studies. After completing the mindset measures, participants responded to a series of open-ended questions about their experience with the study (some of which were related to the initial task) and a demographic questionnaire.

\section{Results}

To test our primary hypotheses, we submitted the eight indices of performance-oriented and mastery-oriented instructional practices to a mixed ANCOVA. This analysis included the target's ability level (high versus low), instructional practice type (mastery- vs. performance-

\footnotetext{
${ }^{3}$ The task required participants to read through a number of fictional student profiles that included grades, standardized test scores, and a trajectory of quiz scores for either math or language arts, and to make a number of ability-related judgments and academic decisions using the information provided to them about each student. More details about this task are available upon request.
} 
oriented), and domain (math vs. language arts) as within-subjects factors, participants' meancentered ability mindset scores as a continuous between-subjects covariate, and all associated two-, three-, and four-way interactions. We conducted an ANCOVA because unlike regression, it enabled us to examine the interaction between a continuous independent variable (i.e., the covariate) and a repeated-measure factor (see Algina, 1982; Thomas, 2009; Thomas et al., 2009, for more detail on this analytic approach). The statistics for all main effects and interactions are reported in Table $2 .{ }^{4}$ To test simple effects, we conducted separate 2 (ability level: low vs. high) $\times 2$ (domain: math vs. language arts) ANCOVAs for each instruction type; statistics for simple effects are reported below.

The results of the analyses showed that participants were significantly more likely to indicate that they would use mastery-oriented practices than performance-oriented practices; however, consistent with previously published findings, this effect was moderated by participants' mindsets (Leroy et al., 2007; Muenks et al., 2015; Park et al., 2016; Stipek et al., 2001). Specifically, the stronger participants' growth mindsets were, the less likely they were to use performance-oriented practices, $F(1,172)=5.30, p=.023, \eta^{2}{ }_{p}=.030$, and the more likely they were to use mastery-oriented practices, $F(1,172)=10.85, p=.001, \eta^{2}{ }_{p}=.059$. Furthermore, consistent with findings from the teacher expectancy literature (Babad, 1993; Jussim, et al., 2009), the analysis also revealed a significant ability level $\times$ instruction type interaction. Specifically, participants were significantly more likely to use performance-oriented practices and less likely to use mastery-oriented practices with low performing students than with high performing students, $F \mathrm{~s}>44.93, p \mathrm{~s}<.001, \eta_{\mathrm{ps}}^{2}>.207$.

\footnotetext{
${ }^{4}$ Because all terms in each analysis were added to the model simultaneously, lower-order terms (including main effects and two- or three-way interactions) should be interpreted as conditional effects (see Aiken \& West, 1991).
} 
Most notably, the expected mindset $\times$ ability level $\times$ instruction type interaction was just above the threshold of significance $(p=.052)$. To explore the nature of this interaction (which was not moderated by domain), we estimated mean ratings at $1 S D$ below the mean of the mindset measure (representing participants with weaker growth mindsets) and $1 S D$ above the mean (representing participants with stronger growth mindsets; Aiken \& West, 1991). As shown in Figure 1, the pattern was generally consistent with our hypothesis: participants with relatively strong growth mindsets differentiated between high and low performing students to a significantly lesser extent than did participants with weaker growth mindsets. Specifically, while both sets of participants reported being more likely to use performance-oriented practices with low ability students than with high ability students, $F \mathrm{~s}>79.26, p \mathrm{~s}<.001, \eta^{2} \mathrm{ps}>.315$, participants with weaker growth mindsets did so to a greater extent than did participants with weaker growth mindsets, as indicated by a marginally significant mindset $\times$ ability level interaction for this instruction type, $F(1,172)=2.84, p=.094, \eta^{2} \mathrm{p}=.016$. Both sets of participants also reported being less likely to use mastery-oriented practices with low ability students than with high ability students, $F_{\mathrm{s}}>14.43, p \mathrm{~s}<.001, \eta^{2} \mathrm{ps}>.077$, but participants with weaker growth mindsets did this to a non-significantly greater extent, $F(1,172)=1.74, p=.189$, $\eta^{2} \mathrm{p}=.010$

Finally, we conducted additional simple effects analyses to examine the associations between mindsets and instructional practices separately for the low and high ability students. ${ }^{5}$ These analyses revealed that the weaker participants' growth mindsets were, the more likely they were to use performance-oriented practices with low ability students, $F(1,172)=6.81, p=.010$,

\footnotetext{
${ }^{5}$ These additional simple effects were derived from a set of ANCOVAs that included participants' mean ratings for performance-oriented or mastery-oriented practices averaged across all of the low ability or high ability scenarios. Mindset was included as a covariate.
} 
$\eta^{2} \mathrm{p}=.038$; whereas this association was not significant when it came to high ability students, $F(1,172)=2.63, p=.107, \eta^{2}{ }_{p}=.015$. In addition, the weaker participants' growth mindsets were, the less likely they were to use mastery-oriented practices with low ability students, $F(1$, $172)=11.55, p<.001, \eta^{2}{ }_{p}=.063$. This was also the case with high ability students, but to a lesser extent, $F(1,172)=7.61, p=.006, \eta_{\mathrm{p}}^{2}=.042$.

\section{Discussion}

In Study 1, we examined the self-reported instructional practices of undergraduate participants enrolled in an educational school course. Consistent with previous studies, we found that participants with weaker growth mindsets were more likely to endorse using performanceoriented practices and less likely to endorse using mastery-oriented instructional practices than participants with stronger growth mindsets. However, in line with our predictions, we also found that these results were moderated by participants' perceptions of the target students' ability

levels. Specifically, participants with relatively weak growth mindsets reported being more likely to use performance-oriented practices and less likely to use mastery-oriented practices with struggling students described as low (versus high) achieving. Participants with stronger growth mindsets also differentiated between low and high ability students, but to significantly lesser extent than participants with weaker growth mindsets.

\section{Study 2}

The aim of Study 2 was to replicate Study 1 with a sample of in-service elementary school teachers. Critically, as opposed to having the teachers report the instructional practices they would engage in with fictional students (as in both Study 1 and Lee's [1996] work), we asked them to report the practices they would use with actual students who they were currently 
working with or had worked with in the past. Together, these changes to our sample and methods allowed for a more generalizable test of our hypothesis.

\section{Method}

Participants. In August and September of 2015, a total of 367 responses were recorded from individuals who completed an online consent form and were connected to the survey. Recruitment emails, which included the incentive of a \$10 Amazon e-gift card, were sent to a list of alumni of the elementary education degree programs at a private university in the Northeast United States $\left(\sim 11 \%\right.$ response rate) ${ }^{6}$ The emails specifically stated that the individual was invited to participate if he/she was "currently working as an elementary school teacher."

In all, 122 teachers were excluded from the analyses reported below because they either failed to complete the study $(N=110)$, they were missing data central to the main dependent measure $(N=11)$, or were missing an excessive amount of data $(N=1) .^{7}$ The final sample consisted of 245 elementary school teachers $(95.1 \%$ female; mean age $=36.7, S D=11.5)$, working primarily at public schools $(75.9 \% ; 10.6 \%$ private; $4.1 \%$ charter; $6.1 \%$ Catholic; and $3.3 \%$ other $){ }^{8}$ The teachers, who had an average of 12.3 years of teaching experience $(S D=9.8)$, estimated that (on average) about $33.7 \%$ of their students were from low income families (e.g., received free lunch).

With respect to the grade level that participants were currently teaching, the distribution was spread fairly evenly across kindergarten to sixth grade, with the smallest percentages of

\footnotetext{
${ }^{6}$ All but one teacher in the final sample indicated that they had received an education degree from the university. ${ }^{7}$ An additional 11 participants completed a preliminary version of the survey that had a minor difference from the final version. Data from these participants were not analyzed. For more information about recruitment, the response rate, the exclusion criteria, and the sequence of analyses, see the supplementary materials.

${ }^{8}$ Of the eight teachers who selected "Other" when reporting what type of school they worked at, four reported working at an international school or a school in a different country, one reported working at a Jewish School, one reported working at a DoDEA school, one reported working at a Title 1 public school, and one reported working at an "urban" school.
} 
participants teaching kindergarten $(7.8 \%)$ and sixth grade $(9.0 \%)$, and the highest percentage teaching fifth grade $(21.7 \%)$. In addition, most of the teachers $(88.2 \%)$ had experience teaching at more than one grade level. With respect to subject matter, $39.6 \%$ of teachers considered English/language arts to be their primary subject, $18.8 \%$ considered math to be their primary subject, and $15.5 \%$ taught special education (the remaining $26.1 \%$ of teachers selected a different subject or chose 'other'); however, $95.9 \%$ of all teachers had experience teaching language arts and $94.3 \%$ had experience teaching math. In addition, some teachers had experience teaching science $(80.8 \%)$, history $(78.4 \%)$, special education $(54.7 \%)$, art (13.1\%), physical education $(6.9 \%)$, and music $(2.4 \%)$.

The racial background of the sample was primarily White $(92.6 \% ; 4.9 \%$ Asian/AsianAmerican; 3.3\% Black/African-American, .4\% Pacific Islander; .4\% Native American or Alaskan; participants could choose multiple categories). A separate question was used to assess Latinx identify (3.3\%). With respect to education level, $13.5 \%$ of teachers reported that a bachelor's degree was the highest academic degree that they had been awarded as part of their education-specific training. The remaining teachers reported having a master's degree or higher. ${ }^{9}$

To get a better sense of the representativeness of our sample, we compared its demographic characteristics to a nationally representative sample of public school teachers, as well as to a representative sample of private school teachers. Note that roughly $80 \%$ of our sample reported working at a traditional public school or charter school, compared to $88 \%$ of the teachers across the two nationally representative samples. As can be seen in Table 1, our sample was fairly similar to both national samples with respect to gender, race, age, and years of

\footnotetext{
${ }^{9}$ One participant did not report age, one did not indicate gender, one did not indicate racial background, one chose "Other" for educational attainment but did not indicate a specific degree, one did not indicate the grade he/she was teaching, and two participants did not provide an estimate of the percentage of students in their school from low income families.
} 
teaching experience. The only substantial difference appears to be the higher percentage of teachers in our sample who received a master's degree, which can perhaps be explained by the professional licensing requirements in the state where the teachers were educated.

\section{Materials.}

Instructional practices. Because Study 2 was conducted as a brief online survey, the teachers were only asked to respond to two scenarios (in a random order); one corresponding to a high ability student and another corresponding to a low ability student. In contrast to Study 1, the domain of the scenarios was manipulated between participants in Study $2\left(N_{\text {math }}=126, N_{\text {verbal }}=\right.$ 119). For each scenario, teachers were prompted to think about a specific student they were working with or had worked with in the past, who they perceived as having high [low] math [verbal] ability. To ensure that these students and their perceived ability levels were especially salient, they were then asked to take two minutes to write a brief description of the student and an explanation of why they considered him/her to have a high [low] level of math [verbal] ability. The teachers were also asked to indicate the grade (K-6) the student was in at the time they worked with him or her. ${ }^{10}$

Next, the teachers were asked to imagine that the student was struggling to complete a "math" ["verbal or language arts"] assignment in their classroom and to rate (in a random order) how likely they would be to engage in each of 10 "teaching behaviors" on a 6-point scale from "Very Unlikely" to "Very Likely." These behaviors (i.e., instructional practices) were revised from Study 1 to improve clarity and reliability (see Table 3 for a full list of items). Again, five of

\footnotetext{
${ }^{10}$ After conducting the analyses reported below, we identified three participants who provided descriptions that seemed to indicate that they did not think about a low or high ability student in the appropriate domain. One of these participants also did not indicate the grade of the high ability student. When we excluded these three participants from the analyses, the three-way interaction of primary interest was still significant, and the effect size was slightly stronger (see the supplementary materials for more details).
} 
the items assessed mastery-oriented instructional practices (e.g., "Suggest strategies that would be helpful for figuring out the answers to the problems or questions he/she is struggling with"), while the remaining five assessed performance-oriented instructional practices ("Give the student solutions to the problems or questions he/she is struggling with"). In order to reduce social desirability bias, we indicated to the teachers that we were interested in the types of teaching behaviors they believe they would actually engage in with that student, and not necessarily how helpful they thought each teaching behavior would be. For each scenario, a mastery-oriented index was created by averaging the five relevant items from the scale $(M \mathrm{~s}=5.11$ and $5.25, S D \mathrm{~s}=$ .59 and $55, \alpha \mathrm{s}=.53$ and $.54, \omega_{\text {ordinal }}=.63$ and .68 , for the low ability and high ability scenario, respectively). And, a performance-oriented index was created by averaging the other five items form the scale $\left(M \mathrm{~s}=2.36\right.$ and $1.91, S D \mathrm{~s}=.74$ and $.68, \alpha \mathrm{s}=.55$ and $.56, \omega_{\text {ordinal }}=.69$ and .70$)$. An exploratory factor analysis (EFA) of the revised scale showed that all items loaded positively onto the appropriate factor (see Table 3 for factor loadings). For a full description of the EFA, see the supplementary materials.

Academic mindsets. Academic mindsets were measured with the same 8-item version of Dweck's (1999) implicit theories of intelligence scale used in Study 1. As in Study 1, the mean $\left(M=4.46, S D=.87, \alpha=.93, \omega_{\text {ordinal }}=.95\right)$ was significantly higher than the midpoint of the scale, $t(244)=17.20, p<.001$, reflecting the fact that $85.3 \%$ of teachers reported scores that were indicative of a growth mindset (i.e., higher than the midpoint of the scale at 3.5). Therefore, the results of our primary analyses are again framed in terms of differences between teachers with relatively strong versus weak growth mindsets.

Naïveté check and special education experience. Two additional factors were assessed as controls for our analyses. First, because research suggests that teachers have become 
increasingly aware of Dweck's research on fixed versus growth mindsets in recent years (e.g., Education Endowment Foundation, 2015, p. 34), the teachers were asked to indicate whether or not they were familiar with this research (coded as $0=$ no, $1=$ yes). The $52.9 \%$ of teachers who answered yes were then asked how familiar (from 1 to 6 ) they were with the research (though only their dichotomous response was used in our analyses). Second, because special education teachers may conceptualize intelligence differently or have more experience with lower ability students than other teachers (Bianco, 2005; Gutshall, 2013), we created a separate variable indicating whether or not participants' reported special education to be their primary subject (coded as $0=$ no, $1=$ yes $[15.5 \%]$ ). Note that one participant did not respond to the dichotomous mindset familiarity question.

Procedure. Study 2 was administered as an online survey using Qualtrics Research Suite. Participants began by completing the instructional practices scale for each of the two teaching scenarios. They then completed a task that pertained to a related but distinct set of hypotheses not discussed in this paper. ${ }^{11}$ This was followed by a classroom management task, which for the sake of clarity and brevity, we present in the supplementary materials. Next, participants completed the general measure of academic mindsets, as well as several other measures described in the supplementary materials (including measures of the teachers' domainspecific mindsets). ${ }^{12}$ Toward the end of the study, participants completed some open-ended questions about their experience with the study, as well as the naïveté check described above.

\footnotetext{
${ }^{11}$ Similar to Study 1, the task required participants to read through a number of fictional student profiles that included a trajectory of exam scores for either math or language arts, and to make numerous ability- and attributionrelated judgments and academic decisions using the information provided to them about each student. The gender of the names assigned to the fictional students was manipulated between participants. More details about this task are available upon request.

${ }^{12}$ Unlike in Study 1, domain-specific mindsets were associated with differential treatment; however, this association varied by domain.
} 
They then completed questionnaires assessing their teaching experience and demographic background.

\section{Results}

Primary analyses. To test our primary hypotheses, we computed indices of participants' mean likelihood of using mastery- and performance-oriented practices in each of the two teaching scenario conditions and submitted these indices to a mixed ANCOVA. This analysis included the target's ability level (high versus low) and instructional practice type (mastery- vs. performance-oriented) as within-subjects factors, domain (math vs. language arts) as a betweensubjects factor, and participants' mean-centered ability mindset scores as a continuous betweensubjects covariate, and all associated two-, three-, and four-way interactions. The statistics for all main effects and interactions are reported in Table 4; statistics for simple effects are reported below. To test simple effects, we conducted separate 2 (domain: math vs. language arts) $\times 2$ (ability level: low vs. high) ANCOVAs for each instruction type; statistics for simple effects are reported below.

As in Study 1, teachers were significantly more likely to indicate that they would use mastery-oriented practices than performance-oriented practices; however, this effect was again moderated by participants' mindsets (Leroy et al., 2007; Muenks et al., 2015; Park et al., 2016; Stipek et al., 2001). Specifically, the stronger teachers' growth mindset were, the less likely they were to use performance-oriented practices, $F(1,241)=15.81, p<.001, \eta^{2} \mathrm{p}=.062$, and the more likely they were to use mastery-oriented practices, $F(1,241)=9.24, p=.003, \eta^{2}{ }_{p}=.037$. Furthermore, consistent with Study 1 and findings from the teacher expectancy literature (Babad, 1993; Jussim et al., 2009), the analysis again revealed a significant ability level $\times$ instruction type interaction. Specifically, teachers were significantly more likely to use performance-oriented 
practices and less likely to use mastery-oriented practices with low ability students than with high ability students, $F \mathrm{~s}>19.51, p \mathrm{~s}<.001, \eta^{2} \mathrm{ps}>.074$.

Most importantly, we observed the same significant mindset $\times$ ability level $\times$ instruction type interaction as in Study 1 (and, again, this effect did not vary by domain). To explore the nature of this interaction, we estimated mean ratings at $1 S D$ below the mean of the mindset measure (representing teachers with weaker growth mindset) and at $1 S D$ above the mean (representing teachers with stronger growth mindset; Aiken \& West, 1991). As shown in Figure 2, the results again supported our hypothesis: teachers with stronger growth mindsets differentiated between high and low performing students to a lesser extent than did participants with stronger growth mindset. Specifically, teachers with weaker growth mindsets again reported being significantly more likely to use performance-oriented practices, $F(1,241)=103.75, p<$ $.001, \eta^{2}{ }_{p}=.301$, and significantly less likely to use mastery-oriented practices, $F(1,241)=$ 20.68, $p<.001, \eta^{2}{ }_{p}=.079$, with low ability students than with high ability students. Teachers with stronger growth mindsets also differentiated between low and high ability students with their use of performance-oriented practices, $F(1,241)=53.92, p<.001, \eta^{2}=.183$, but did so to a lesser extent than teachers with weaker growth mindsets, as indicated by the statistically significant mindset $\times$ ability level interaction for this instruction type, $F(1,241)=4.10, p=.044$, $\eta^{2} \mathrm{p}=.017$. By contrast, teachers with stronger growth mindsets only differentiated between low and high ability students with their use of mastery-oriented practices to a marginally significant degree, $F(1,241)=2.80, p=.096, \eta^{2} \mathrm{p}=.011$. As a result, they showed significantly less differential treatment than teachers with weaker growth mindsets when it came to using masteryoriented practices; as indicated by the significant mindset $\times$ ability level interaction for this instruction type, $F(1,241)=4.13, p=.043, \eta^{2}=.017$. 
We conducted additional simple effects analyses to examined the associations between mindsets and instructional practices separately for the low and high ability students. ${ }^{13}$ The analyses showed that the weaker participants' growth mindsets were, the more likely they were to use performance-oriented practices with both low and high ability students, $F \mathrm{~s}=18.51$ and $8.63, p<.001$ and $p=.004, \eta^{2} \mathrm{p}^{\text {s }}=.071$ and .035 (respectively); however, the size of this effect was more than twice as large for low ability students as it was for high ability students. In addition, the weaker participants' growth mindsets were, the less likely they were to use masteryoriented practices with low ability students, $F(1,241)=12.78, p<.001, \eta^{2} \mathrm{p}=.050$; however, this association was only marginally significant when it came to high ability students, $F(1,241)$ $=3.09, p=.080, \eta_{\mathrm{p}}^{2}=.013$.

Analyses controlling for naïveté and special education focus. Finally, we conducted an additional ANCOVA that included the dichotomous measures of teachers' familiarity with mindset research and their focus on special education as covariates. SPSS automatically generated two- and three-way interaction terms between each covariate and each withinparticipant factor. Interaction terms between each covariate and other between-participant variables were not included in the model.

As shown in Table 4, this analysis yielded a significant main effect of mindset familiarity, which was qualified by a significant mindset familiarity $\times$ instruction type interaction. That is, teachers who were familiar with research on growth mindsets were significantly less likely to use performance-oriented practices than teachers who were unfamiliar

\footnotetext{
13 These additional simple effects were derived from an additional set of ANCOVAs that each included participants' mean ratings for performance-oriented or mastery-oriented practices for the low ability or high ability scenario; domain was included as a between-subjects factor.
} 
with this research, $F(1,238)=25.05, p<.001, \eta^{2} \mathrm{p}=.095$; however, they were no more likely to use mastery-oriented practices, $F(1,238)=.56, p=.455, \eta^{2}{ }_{\mathrm{p}}=.002$.

Most notably, the inclusion of these covariates did not change the significance of any of the main effects or interactions, though it did reduce the corresponding effect sizes and reduce some of the simple effects to non-significance. For instance, although teachers with weaker growth mindsets differentiated their use of performance-oriented practices to a greater extent than teachers with stronger growth mindset, $F \mathrm{~S}=93.76$ and $51.68, p s<.001, \eta_{\mathrm{p}}^{2}=.283$ and .178 (respectively), the simple effect of mindsets on differential treatment for (i.e., the mindset $\times$ ability level interaction) performance-oriented practices was only marginally significant, $F(1$, $238)=2.97, p=.086, \eta_{\mathrm{p}}^{2}=.012$. Similarly, although teachers with weaker growth mindsets differentiated their use of mastery-oriented practices between low and high ability students to a greater extent than teachers with stronger growth mindset, $F_{\mathrm{S}}=16.05$ and $4.15, p<.001$ and $p=$ $.043, \eta_{p}^{2}=.063$ and .017 (respectively), the simple effect of mindsets on differential treatment for mastery-oriented practices was not significant, $F(1,238)=1.83, p=.178, \eta^{2}{ }_{p}=.008$.

Nevertheless, the overall relation between teachers' growth mindsets and their differential use of both instructional practices (i.e., the mindset $\times$ ability level $\times$ instruction type interaction) was still significant, and neither of the covariates was significantly associated with the differentiation of instruction based on ability level $(p s>.16)$. Additional simple effects for this analysis are reported in the supplementary materials.

\section{Analysis Including Scenario Order}

We conducted an additional analysis to determine whether scenario order (i.e., whether teachers were asked to think about a high or low ability student first) moderated any of the primary effects of interest by adding order as a variable (and all corresponding interaction terms) 
to our primary ANCOVA analysis. Although the mindset $\times$ ability level $\times$ instruction type remained significant, $F(1,237)=9.58, p=.002, \eta^{2} \mathrm{p}=.039$, it was marginally moderated by order, $F(1,237)=3.56 p=.060, \eta^{2} \mathrm{p}=.015$. The three-way interaction was significant when the high ability scenario was presented first, $F(1,237)=11.68, p<.001, \eta^{2} \mathrm{p}=.047$, but not when it was presented second, $F(1,237)=.78, p=.378, \eta_{\mathrm{p}}^{2}=.003$. Other significant order effects are described in the supplementary materials.

\section{Discussion}

The aim of Study 2 was to replicate and extend Study 1 by having a sample of in-service elementary school teachers report on the instructional practices that they would use with actual students. Consistent with the results of Study 1, we found that the weaker teachers' growth mindsets were, the more likely they were to differentiate between low and high ability students in their use of use instructional practices. Specifically, teachers with weaker growth mindsets were more likely to use performance-oriented practices and less likely to use mastery-oriented practices with students they perceived to be low (vs. high) in ability. This pattern was significantly attenuated among teachers with stronger growth mindsets.

\section{General Discussion}

Across two studies, we found that participants with weaker (vs. stronger) growth mindsets were more likely to differentiate between low and high ability elementary school students in their use of performance- and mastery-oriented practices. The patterns were the same regardless of whether the participants were undergraduates thinking about fictional elementary school children (Study 1) or in-service teachers thinking about real children that they had worked with (Study 2). Specifically, individuals with weaker growth mindsets were more likely to use performance-oriented practices and less likely to use mastery-oriented practices with low ability 
students than with high ability students. Individuals with stronger growth mindsets also engaged in this type of differential treatment, but not to the same extent.

\section{Theoretical and Practical Implications}

The present findings have important implications for the teacher mindset literature. Specifically, prior studies have demonstrated that teachers with weaker growth mindsets are more likely than teachers with stronger growth mindsets to engage in performance-oriented practices and less likely to engage in mastery-oriented practices (Leroy et al., 2007; Park et al., 2016; Stipek et al., 2001). The current research replicates these effects, but also suggests that their strength may depend on teachers' perceptions of the students they are targeting with these practices. When participants anticipated interacting with students they perceived to be low in ability, we found a strong association between their mindsets and instructional practices. By contrast, for students they perceived to be high in ability, this association was weaker (indicated by the mindset $\times$ student ability $\times$ instructional practice type interactions and associated simple effects).

The current research also replicates findings from the teacher expectancy literature, showing that teachers sometimes engage in more supportive instructional practices with high ability students, who they perceive as capable of substantial growth. While this kind of differential treatment can lead to self-fulfilling prophecy effects (e.g., Kuklinski \& Weinstein, 2001), reviews of this literature (Jussim et al., 2009) suggest that teacher expectancy effects are small on average. One reason for these small effects may be that some teachers are more prone to differential treatment than others and that by averaging across all teachers, the effects become attenuated. Thus, an important contribution of the present studies is that they establish teachers' 
growth mindsets as an individual difference variable that can potentially be used to identify teachers who might be particularly susceptible to teacher expectancy effects.

\section{Explaining the Association Between Teacher Mindsets and Differential Treatment}

Based on the large main effect of instruction type in both studies (see Figures 1 and 2), it is clear that college students and elementary school teachers believe that mastery-oriented and autonomy-supportive practices are more constructive than performance-oriented and controlling practices when it comes to working with individual children. Consistent with this belief, a metaanalysis (Rolland, 2012) found that students' perceptions of their classrooms as being masteryoriented were positively associated with a sense of competence, whereas perceptions of classrooms as being performance-oriented were negatively associated with academic performance. In this case, one can ask why some teachers would be less likely to use more constructive practices, and more likely to use less constructive practices, with low ability students than with high ability students. That is, why would they not use mastery-oriented practices equally with all students?

One possibility, which we raised in the introduction, is that teachers who believe that intelligence or ability cannot be substantially improved (i.e., teachers with weaker growth mindsets) may tend to interpret the struggles of low achieving students as indicating that these students have reached the limits of their ability. In contrast, the same teachers may construe the struggles of high achieving students as indicating that these students are working hard on challenging tasks to build mastery. Based on these inferences, teachers with weak growth mindsets may conclude that students they perceive as having low ability are less likely than students they perceive as having high ability to substantially benefit from instructional practices allowing them to direct their own learning (i.e., mastery-oriented practices) and more likely to 
benefit from practices meant to ensure they will meet the minimum performance standards for the class (i.e., performance-oriented practices). In contrast, teachers who believe all students are capable of intellectual growth (i.e., those with stronger growth mindsets) are likely to perceive the struggles of both low and high ability students as mere bumps on the road to mastery. Thus, they should be less likely than teachers with weaker growth mindsets to differentiate between low and high ability students in their use of mastery- and performance-oriented instructional practices.

Another explanation for the association between teachers' mindsets and their differential treatment of students pertains to what teachers believe about the malleability of their own intelligence, rather than the intelligence of their students. Specifically, teachers who believe themselves to have a fixed amount of intellectual ability may be particularly concerned with demonstrating that this amount is high enough for them to be a successful teacher-just as students with fixed mindsets tend to be concerned with demonstrating that they are smart enough to do well academically (Haimovitz, Wormington, \& Corpus, 2011; Mueller \& Dweck, 1998; Stipek \& Gralinski, 1996). Consequently, they may adopt performance goals aimed at maximizing outcomes that indicate high teaching ability or minimizing outcomes that indicate low teaching ability, such as high or low student test scores (see Butler, 2007). These goals may, in turn, be positively associated with their use of performance-oriented instructional practices (and thus negatively associated with their use of mastery-oriented practices) with low ability students, as it is these students who are in danger of bringing down the class average. (For a series of exploratory analyses investigating this possibility, see the supplementary materials.)

Finally, in attempting to explain the relation between teacher mindsets and differential treatment, it is important to note that even participants with stronger growth mindsets appeared 
to engage in differential treatment to some extent. For instance, participants with stronger growth mindsets were more likely to use performance-oriented practices with low ability students than with high ability students in both studies, though this effect was generally weaker than it was for participants with weaker growth mindsets. One possibility is that some performance-oriented and controlling practices included in our measure may not necessarily be unconstructive ways of working with low ability students. For example, “[giving] the student an easier assignment to work on" may actually be adaptive when the assignment is beyond the student's zone of proximal development (Reeve, 2006). Furthermore, when low ability students struggle (as depicted in our scenarios), it is more likely to be because the assignment is too challenging compared to when high ability students struggle. Thus, in some circumstances, it may be appropriate for teachers to use performance-oriented practices more often with low ability students than with high ability students. However, one should note that (regardless of the teacher's intention) substituting an easier task may be perceived by children as sign that the teacher does not think they are capable of succeeding on the current assignment (Butler, 1994); and, this perception may undermine their academic motivation.

Additional research is needed to determine whether the self-reported differential treatment in the present studies actually increases or decreases any disparities in performance between students initially perceived to be low versus high in ability. For example, teachers with strong growth mindsets may be able to differentiate between low and high ability students in more adaptive ways compared to teachers with weak growth mindsets. If so, the relation between differential treatment and student outcomes might vary based on the growth mindset of the teacher.

\section{Limitations and Future Directions}


Although the present studies have important implications for theory and practice, they also have several limitations that could be addressed by future studies. First, generalizability from the current samples is somewhat limited. The first study was conducted with a convenience sample of undergraduates (enrolled in an educational school course) who were asked to imagine themselves as teachers and the second study was conducted with a sample of teachers who were alumni of the same school. Furthermore, there may have been selection effects in our recruitment of teachers in Study 2, as a relatively small percentage of the teachers contacted by email responded to our request. Nevertheless, we feel that these limitations are somewhat outweighed by the strength of our sampling methodology. Across the studies, we were able to show that the association between mindsets and differential treatment emerged for individuals with little or no teaching experience, as well as for a group of teachers with more than 12 years of experience on average. In addition, our Study 2 sample included teachers who were presumably from a broad range of schools/districts. Thus, although the sample may not be representative of any one district, it may be more representative of the kinds of teachers found across districts (though teachers were similar in their training before joining those districts).

Another limitation of our studies is that they relied on participants' self-reported practices. In Study 1, participants were presented with fictional students and asked to imagine these students in different scenarios. Study 2 was more environmentally valid because it asked teachers to think about actual students. However, these teachers were still asked to imagine working with these students in different scenarios and to self-report the likelihood of using various instructional practices. A next step would be to see if teachers' mindsets predict the kinds of instructional practices they use in real classrooms. An observational study by Stipek et al. (2001) suggests that these practices can be reliably measured via classroom observation. In 
addition, we may actually find that the effects that emerge in actual classrooms are stronger than the effects that emerge through self-report, due to a reduction in social desirability bias.

A final limitation is that the current studies measured teachers' mindsets and, thus, cannot make claims about the causal effect of mindsets on teachers' practices. Future studies involving manipulations of teachers' mindsets are needed to establish this causal link. Such studies will be useful in guiding translational research aimed at increasing teachers' use of constructive instructional practices with both high and low ability students. 


\section{References}

Aiken, L. S., West, S. G. (1991). Multiple regression: Testing and interpreting interactions. Thousand Oaks, CA: Sage.

Algina, J. (1982). Remarks on the analysis of covariance in repeated measures designs. Multivariate Behavioral Research, 17, 117-130.

Babad, E. (1993). Teachers' differential behavior. Educational Psychology Review, 5, 347-376.

Babad, E., Inbar, J., \& Rosenthal, R. (1982). Pygmalion, Galatea, and the Golem: Investigations of biased and unbiased teachers. Journal of Educational Psychology, 74, 459-474.

Bianco, M. (2005). The effects of disability labels on special education and general education teachers' referrals for gifted programs. Learning Disability Quarterly, 28, 285-293.

Black, A., \& Deci, E. (2000). The effects of instructors' autonomy support and students' autonomous motivation on learning organic chemistry: A self-determination theory perspective. Science Education, 84, 740 -756.

Boggiano, A., Flink, C., Shields, A., Seelbach, A., \& Barrett, M. (1993). Use of techniques promoting students' self-determination: Effects on students' analytic problem-solving skills. Motivation and Emotion, 17, 319 -336.

Bohlmann, N., \& Weinstein, F. (2013). Classroom context, teacher expectations, and cognitive level: Predicting children's math ability judgments. Journal of Applied Developmental Psychology, 34, 288-298.

Brattesani, K. A., Weinstein, R. S., \& Marshall, H. H. (1984). Student perceptions of differential teacher treatment as moderators of teacher expectation effects. Journal of Educational Psychology, 76(2), 236-247. 
Brophy, J., \& Good, T. (1970). Teachers' communication of differential expectations for children's classroom performance: Some behavioral data. Journal of Educational Psychology, 61, 365-374.

Burnette, J. L., O'Boyle, E. H., VanEpps, E. M., Pollack, J. M., \& Finkel, E. J. (2013). Mind-sets matter: A meta-analytic review of implicit theories and self-regulation. Psychological Bulletin, 139, 655.

Butler, R. (1994). Teacher communications and student interpretations: Effects of teacher responses to failing students on attributional inferences in two age groups. British Journal of Educational Psychology, 64(2), 277-294.

Butler, R. (2007). Teachers' achievement goal orientations and associations with teachers' help seeking: Examination of a novel approach to teacher motivation. Journal of Educational Psychology, 99, 241-252.

Chalmers, R. P. (2018). On misconceptions and the limited usefulness of ordinal alpha. Educational and Psychological Measurement, 78(6), 1056-1071.

Deci, E. L., Spiegel, N. H., Ryan, R. M., Koestner, R., \& Kauffman, M. (1982). Effects of performance standards on teaching styles: Behavior of controlling teachers. Journal of educational psychology, 74(6), 852-859.

De Meyer, J., Tallir, I., Soenens, B., Vansteenkiste, M., Aelterman, N., Van den Berghe, L., Speleers, L., Haerens, L. (2014). Does observed controlling teaching behavior relate to students' motivation in physical education? Journal of Educational Psychology, 106, 541-554. 
Doabler, C., Nelson, N., Kosty, D., Fien, H., Baker, S., Smolkowski, K., Clarke, B. (2014). Examining teachers' use of evidence-based practices during core mathematics instruction. Assessment for Effective Intervention 39, 99-111.

Dunn, T. J., Baguley, T., \& Brunsden, V. (2014). From alpha to omega: A practical solution to the pervasive problem of internal consistency estimation. British Journal of Psychology, 105(3), 399-412.

Dweck, C. S. (1999). Self-theories: Their role in motivation, personality, and development. New York, NY: Psychology Press.

Dweck, C. S., \& Leggett, E. L. (1988). A social-cognitive approach to motivation and personality. Psychological review, 95(2), 256-273.

Dweck, C. S., \& Molden, D. (2017). Mindsets: Their impact on competence motivation and acquisition. In A. J. Elliott, C. S. Dweck, \& D. S. Yeager (Eds.), Handbook of competence and motivation: Theory and Application (2nd ed., pp. 135-154). New York, NY: Guilford.

Education Endowment Foundation. (2015). Changing mindsets: Evaluation report and executive summary. Retrieved from https://v1.educationendowmentfoundation.org.uk/uploads/pdf/Changing_Mindsets.pdf

Flink, C., Boggiano, A. K., \& Barrett, M. (1990). Controlling teaching strategies: Undermining children's self-determination and performance. Journal of Personality and Social Psychology, 59(5), 916-924.

Gadermann, A. M., Guhn, M., \& Zumbo, B. D. (2012). Estimating ordinal reliability for Likerttype and ordinal item response data: A conceptual, empirical, and practical guide. Practical Assessment, Research \& Evaluation, 17, 1-13. 
Goldring, R., \& Gray, L., \& Bitterman, A. (2013). Characteristics of public and private elementary and secondary school teachers in the United States: Results from the Schools and Staffing Survey. Washington, DC: National Center for Education Statistics.

Good, T., \& Brophy, J. (1974). Changing teacher and student behavior: An empirical investigation. Journal of Educational Psychology 66, 390-405.

Grolnick, W. S., \& Ryan, R. M. (1987). Autonomy in children's learning: An experimental and individual difference investigation. Journal of Personality and Social Psychology: Attitudes and Social Cognition, 52, 890-898.

Gutshall, C. A. (2013). Teacher's mindsets for students with and without disabilities. Psychology in the Schools, 50, 1073-1083.

Haimovitz, K., Wormington, S. V., \& Corpus, J. H. (2011). Dangerous mindsets: How beliefs about intelligence predict motivational change. Learning and Individual Differences, 21, $747-752$

Hardre, P., \& Reeve, J. (2003). A motivational model of rural students' intentions to persist in, versus drop out of, high school. Journal of Educational Psychology, 95, 347-356.

Jang, H., Reeve, J., Ryan, R. M., \& Kim, A. (2009). Can self-determination theory explain what underlies the productive, satisfying learning experiences of collectivistically oriented Korean students? Journal of Educational Psychology, 101, 644-661.

Jonsson A.C., \& Beach, D. (2012) Predicting the use of praise among pre-service teachers: The influence of implicit theories of intelligence, social comparison and stereotype acceptance. Education Inquiry, 3, 259-281. 
Jussim, L., Robustelli, S. L., \& Cain, T. R. (2009). Teacher expectations and self-fulfilling prophecies. In K. R. Wenzel, \& A. Wigfield (Eds.), Handbook of motivation at school (pp. 349-380). New York, NY: Routledge/Taylor \& Francis Group.

Kuklinski, M. R., \& Weinstein, R. S. (2001). Classroom and developmental differences in a path model of teacher expectancy effects. Child development, 72(5), 1554-1578.

Lee, K. (1996). A study of teacher responses based on their conceptions of intelligence. The Journal of Classroom Interaction, 31, 1-12.

Leroy, N., Bressoux, P., Sarrazin, P., \& Trouilloud, D. (2007). Impact of teachers' implicit theories and perceived pressures on the establishment of an autonomy supportive climate. European Journal of Psychology of Education, 22, 529-545.

McNeish, D. (2018). Thanks coefficient alpha, we'll take it from here. Psychological Methods, $23(3), 412-433$.

Meece, J., Anderman, E., \& Anderman, L. (2006). Classroom goal structure, student motivation, and academic achievement. Annual Review of Psychology, 57, 487-503.

Midgley, C., Maehr, M. L., Hruda, L. Z., Anderman, E., Anderman, L., Freeman, K. E., \& Urdan, T. (2000). Manual for the patterns of adaptive learning scales (PALS). Ann Arbor, MI: University of Michigan.

Moorman, E. A., \& Pomerantz, E. M. (2010). Ability mindsets influence the quality of mothers' involvement in children's learning: An experimental investigation. Developmental Psychology, 46, 1354-1362.

Mueller, C. M., \& Dweck, C. S. (1998). Praise for intelligence can undermine children's motivation and performance. Journal of personality and social psychology, 75(1), 33-52. 
Muenks, K., Miele, D. B., Ramani, G. B., Stapleton, L. M., \& Rowe, M. L. (2015). Parental beliefs about the fixedness of ability. Journal of Applied Developmental Psychology, 41, 78-89.

Munro, J. (1999). Learning more about learning improves teacher effectiveness. School Effectiveness and School Improvement 10, 151-171.

Niemiec, C. P., \& Ryan, R. M. (2009). Autonomy, competence, and relatedness in the classroom: Applying self-determination theory to educational practice. School Field, 7(2), 133-144.

Park, D., Gunderson, E. A., Tsukayama, E., Levine, S. C., \& Beilock, S. L. (2016). Young children's motivational frameworks and math achievement: Relation to teacher-reported instructional practices, but not teacher theory of intelligence. Journal of Educational Psychology, 108, 300-313.

Patall, E. A., Dent, A. L., Oyer, M., \& Wynn, S. R. (2013). Student autonomy and course value: The unique and cumulative roles of various teacher practices. Motivation and Emotion, $37,14-32$.

Patrick, H., Anderman, L., Ryan, A., Edelin, K., \& Midgley, C. (2001). Teachers' communication of goal orientations in four fifth-grade classrooms. The Elementary School Journal, 102, 35-58.

Rattan, A., Good, C., \& Dweck, C. S. (2012). "It's ok — Not everyone can be good at math": Instructors with an entity theory comfort (and demotivate) students. Journal of Experimental Social Psychology, 48, 731-737.

Reeve, J. (2006). Teachers as Facilitators: What autonomy supportive teachers do and why their students benefit. The Elementary School Journal, 106, 225-236. 
Reeve, J. (2012). A self-determination theory perspective on student engagement. In S. L. Christenson, A. L. Reschly \& C. Wylie (Eds.), Handbook of research on student engagement (pp. 149-172). New York, NY: Springer Science + Business Media.

Reeve, J., \& Jang, H. (2006). What teachers say and do to support students' autonomy during a learning activity. Journal of Educational Psychology, 98, 209-218.

Reeve, J., Jang, H., Carrell, D., Jeon, S., \& Barch, J. (2004). Enhancing students' engagement by increasing teachers' autonomy support. Motivation and Emotion, 28, 147-169.

Renkl, A., \& Helmke, A. (1992). Discriminant effects of performance-oriented and structureoriented mathematics tasks on achievement growth. Contemporary Educational Psychology, 17, 47-55.

Retelsdorf, J., Butler, R., Streblow, L., \& Schiefele, U. (2010). Teachers' goal orientations for teaching: Associations with instructional practices, interest in teaching, and burnout. Learning and Instruction, 20, 30-46.

Rolland, R.G. (2012). Synthesizing the evidence on classroom goal structures in middle and secondary schools: A meta-analysis and narrative review. Review of Educational Research, 82(4), 396-435.

Ryan, R. M., \& Deci, E. L. (2016). Facilitating and hindering motivation, learning, and wellbeing in schools: Research and observations from self-determination theory. In K. R. Wentzel \& D. B. Miele (Eds.), Handbook on motivation at schools (pp. 96-119). New York, NY: Routledge.

Sarrazin, P., Tessier, D., Pelletier, L., Trouilloud, D., Chanal, J. (2006). The effects of teachers' expectations about students' motivation on teachers' autonomy-supportive and controlling behaviors. International Journal of Sport and Exercise Psychology, 4, 283-301. 
Shim, S. S., Cho, Y., \& Cassady, J. (2013). Goal structures: The role of teachers' achievement goals and theories of intelligence. Journal of Experimental Education, 81, 84-104.

Soenens, B., \& Vansteenkiste, M. (2005). Antecedents and outcomes of self-determination in 3 life domains: The role of parents' and teachers' autonomy support. Journal of Youth and Adolescence, 34, 589-604.

Stipek, D. J., \& Gralinski, J. H. (1996). Children's beliefs about intelligence and school performance. Journal of Educational Psychology, 88, 397-407.

Stipek, D. J., Salmon, J. M., Givvin, K. B., Kazemi, E., Saxe, G., \& MacGyvers, V. L. (1998). The value (and convergence) of practices suggested by motivation research and promoted by mathematics education reformers. Journal for Research in Mathematics Education, 29, 465-488.

Stipek, D. J., Givvin, K. B., Salmon, J. M., \& MacGyvers, V. L. (2001). Teachers' beliefs and practices related to mathematics instruction. Teaching and Teacher Education, 17, 213226.

Stronge, J., Ward, T., \& Grant, L. (2011). What makes good teachers good?: A cross-case analysis of the connection between teacher effectiveness and student achievement. Journal of Teacher Education, 62, 339-355.

Thomas, M. S. C. (2009, June 10). A note on repeated measures ANCOVA. Retrieved from: http://www.psyc.bbk.ac.uk/research/DNL/stats/Repeated_Measures_ANCOVA.html

Thomas, M. S. C., Annaz, D., Ansari, D., Serif, G., Jarrold, C., \& Karmiloff-Smith, A. (2009). Using developmental trajectories to understand developmental disorders. Journal of Speech, Language, and Hearing Research, 52, 336-358. 
Tomic, W. (1989). Teaching behavior and student learning outcomes in Dutch mathematics classrooms. Journal of Educational Research, 82, 339-347. 
Table 1. Demographic data for national representative samples of U.S. public and private school teachers and for the sample in Study 2.

\begin{tabular}{|c|c|c|c|}
\hline Demographic Variable & $\begin{array}{c}\text { Public School } \\
\text { Teachers }\end{array}$ & $\begin{array}{c}\text { Private School } \\
\text { Teachers }\end{array}$ & $\begin{array}{l}\text { Study } 2 \\
\text { Sample }\end{array}$ \\
\hline \multicolumn{4}{|l|}{ Sex } \\
\hline Male & $10.7 \%$ & $14.0 \%$ & $4.9 \%$ \\
\hline Female & $89.3 \%$ & $86.0 \%$ & $95.1 \%$ \\
\hline \multicolumn{4}{|l|}{ Race/ethnicity ${ }^{\text {a }}$} \\
\hline Hispanic, regardless of race & $8.7 \%$ & $7.1 \%$ & $3.3 \%$ \\
\hline White, non-Hispanic & $81.2 \%$ & $85.6 \%$ & $88.6 \%$ \\
\hline Black or African-American, non-Hispanic & $7.1 \%$ & $4.3 \%$ & $2.9 \%$ \\
\hline Asian, non-Hispanic & $1.7 \%$ & $2.2 \%$ & $4.1 \%$ \\
\hline Native Hawaiian/Pacific Islander, non-Hispanic & $\ddagger$ & $\ddagger$ & $.0 \%$ \\
\hline American Indian/Alaska Native, non-Hispanic & $.4 \%$ & 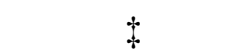 & $.0 \%$ \\
\hline Two or more races, non-Hispanic & $.8 \%$ & $0.6 \%$ ! & $1.2 \%$ \\
\hline \multicolumn{4}{|l|}{ Age } \\
\hline Average & 42.4 years & 44.3 years & 36.7 years \\
\hline Under 30 & $14.9 \%$ & $17.8 \%$ & $34.8 \%$ \\
\hline 30 to 49 & $54.3 \%$ & $42.8 \%$ & $48.0 \%$ \\
\hline 50 to 54 & $12.3 \%$ & $11.2 \%$ & $6.1 \%$ \\
\hline 55 and over & $18.5 \%$ & $28.2 \%$ & $11.1 \%$ \\
\hline \multicolumn{4}{|l|}{ Highest degree earned ${ }^{b}$} \\
\hline Less than bachelor's & $3.2 \%$ & $8.4 \%$ & -- \\
\hline Bachelor's & $41.2 \%$ & $52.8 \%$ & $13.5 \%$ \\
\hline Master's & $47.3 \%$ & $32.7 \%$ & $82.4 \%$ \\
\hline Higher than a master's ${ }^{c}$ & $8.4 \%$ & $6.1 \%$ & $4.1 \%$ \\
\hline \multicolumn{4}{|l|}{ Years of teaching experience } \\
\hline Average & 14.0 years & 14.6 years & 12.3 years \\
\hline Less than 4 & $10.5 \%$ & $16.1 \%$ & $19.6 \%$ \\
\hline 4 to 9 & $28.2 \%$ & $26.9 \%$ & $29.8 \%$ \\
\hline 10 to 14 & $20.7 \%$ & $16.7 \%$ & $15.9 \%$ \\
\hline 15 or more & $40.6 \%$ & $40.3 \%$ & $34.7 \%$ \\
\hline
\end{tabular}

Note: Data for the nationally representative samples of public and private school teachers are from the 2011-2012 Schools and Staffing Survey (SASS), administered by the National Center for Education Statistics (NCES) of the U.S. Department of Education (Goldring, Gray, Bitterman, and Broughman, 2013). For this data, "detail may not sum to totals because of rounding and because some data are not shown." Also, note that data for the public school sample was only for teachers in primary schools, defined as "those with at least one grade lower than 5 and no grade higher than 8 ," and did not include teachers in "combined schools." Similarly, the data for the private school sample was only for teachers in elementary schools, defined as "those with any of grades K-6 and none of grades 9-12," and did not include teachers from "combined schools."

${ }^{a}$ The race/ethnicity percentages for our sample do not exactly match what is reported in the text because the categories in this table are mutually exclusive.

${ }^{b}$ Note that our question about degree attainment, unlike the questions on the NCES surveys, was framed in terms of "education-specific training." "Less than a bachelor's" was not one of the options; though no participants who selected "Other" indicated less than a bachelor's in their open-ended response. One participant marked "Other" but did not indicate a specific degree - this response was coded as missing.

${ }^{c}$ For the NCES data, "higher than a master's degree is defined as a teacher who completed any of the following: an educational specialist or professional diploma, a certificate of advanced graduate studies, or a doctorate or first professional degree." For our own data, we defined this category as any participant who selected the EdD option or who selected "Other" and appeared to specify a PhD, a CAGS, or a $6^{\text {th }}$ year degree (participants who specified post-master's work/credits were not included in this category).

\$ According to NCES, "Reporting standards not met. The coefficient of variation (CV) for this estimate is 50 percent or greater (i.e., the standard error is 50 percent or more of the estimate) or the response rate is below 50 percent." 
Table 2. Summary of ANCOVA Results for Self-Reported Teaching Practices, Study 1.

\begin{tabular}{|c|c|c|c|}
\hline Variable & $F$ & $p$ & $\eta_{\mathrm{p}}^{2}$ \\
\hline Domain (D) & 1.28 & .259 & .007 \\
\hline Mindset (M) & .05 & .831 & $<.001$ \\
\hline Ability Level (AL) & 70.89 & $<.001$ & .292 \\
\hline Instruction Type (IT) & $1,800.77$ & $<.001$ & .913 \\
\hline $\mathrm{D} \times \mathrm{M}$ & .11 & .745 & $<.001$ \\
\hline $\mathrm{D} \times \mathrm{AL}$ & .46 & .497 & .003 \\
\hline $\mathrm{D} \times \mathrm{IT}$ & 1.35 & .248 & .008 \\
\hline $\mathrm{M} \times \mathrm{AL}$ & .42 & .520 & .002 \\
\hline $\mathbf{M} \times \mathbf{I T}$ & 14.77 & $<.001$ & .079 \\
\hline $\mathbf{A L} \times \mathbf{I T}$ & 202.10 & $<.001$ & .540 \\
\hline $\mathrm{D} \times \mathrm{M} \times \mathrm{AL}$ & .10 & .750 & $<.001$ \\
\hline $\mathrm{D} \times \mathrm{M} \times \mathrm{IT}$ & .90 & .344 & .005 \\
\hline $\mathrm{D} \times \mathrm{AL} \times \mathrm{IT}$ & .03 & .868 & $<.001$ \\
\hline $\mathbf{M} \times \mathbf{A L} \times \mathbf{I T}$ & 3.84 & .052 & .022 \\
\hline $\mathrm{D} \times \mathrm{M} \times \mathrm{AL} \times \mathrm{IT}$ & .01 & .906 & $<.001$ \\
\hline
\end{tabular}

Note: Primary effects of interest are in bold. $d f_{\mathrm{s}}=1,172$. 
Table 3. Standardized loadings for two-factor solution corresponding to the high and low ability scenario scenarios in Study 2.

\begin{tabular}{|c|c|c|c|c|}
\hline \multirow[b]{2}{*}{ Item } & \multicolumn{2}{|c|}{ High Ability } & \multicolumn{2}{|c|}{ Low Ability } \\
\hline & Factor 1 & Factor 2 & Factor 1 & Factor 2 \\
\hline \multicolumn{5}{|l|}{ Mastery-oriented instructional practices } \\
\hline $\begin{array}{l}\text { 1. Suggest strategies that would be helpful for figuring out the } \\
\text { answers to the problems or questions he/she is struggling with. }\end{array}$ & -- & 0.48 & -- & 0.40 \\
\hline $\begin{array}{l}\text { 2. Explain how this assignment may be useful in the real world } \\
\text { and relevant to his/her interests. }\end{array}$ & -- & 0.52 & -- & 0.49 \\
\hline 3. Ask the student to explain the thinking behind his/her answers. & -- & 0.64 & -- & 0.65 \\
\hline $\begin{array}{l}\text { 4. Ask the student questions that will prompt him/her to think } \\
\text { critically about his/her approach to each problem or question. }\end{array}$ & -- & 0.70 & -- & 0.61 \\
\hline $\begin{array}{l}\text { 5. Encourage the student to keep working hard on the } \\
\text { assignment. }\end{array}$ & -- & 0.39 & -- & 0.35 \\
\hline \multicolumn{5}{|l|}{ Performance-oriented instructional practices } \\
\hline $\begin{array}{l}\text { 6. Give the student solutions to the problems or questions he/she } \\
\text { is struggling with. }\end{array}$ & 0.53 & -- & 0.53 & -- \\
\hline $\begin{array}{l}\text { 7. Remind the student that he/she needs to finish the assignment } \\
\text { because it will count toward his/her final grade. }\end{array}$ & 0.62 & -- & 0.51 & -- \\
\hline $\begin{array}{l}\text { 8. Offer the student rewards and/or incentives for correct } \\
\text { responses. }\end{array}$ & 0.63 & -- & 0.60 & -- \\
\hline $\begin{array}{l}\text { 9. Tell the student that other children in the class found the } \\
\text { assignment to be easy. }\end{array}$ & 0.60 & -.35 & 0.70 & -- \\
\hline 10. Give the student an easier assignment to work on. & 0.42 & -- & 0.42 & -- \\
\hline
\end{tabular}

Note. Loadings less than $|.3|$ are suppressed. 
Table 4. Summary of ANCOVA Results for Self-Reported Teaching Practices.

\begin{tabular}{|c|c|c|c|c|c|c|}
\hline \multirow[b]{2}{*}{ Variable } & \multicolumn{3}{|c|}{ Model 1} & \multicolumn{3}{|c|}{ Model 2} \\
\hline & $F$ & $p$ & $\eta_{\mathrm{p}}^{2}$ & $F$ & $p$ & $\eta_{\mathrm{p}}^{2}$ \\
\hline Domain (D) & 2.30 & .131 & .009 & 2.55 & .111 & .011 \\
\hline Mindset (M) & 1.59 & .209 & .007 & .02 & .894 & $<.001$ \\
\hline Ability Level (AL) & 44.22 & $<.001$ & .155 & 18.63 & $<.001$ & .073 \\
\hline Instruction Type (IT) & $3,588.88$ & $<.001$ & .937 & 1418.26 & $<.001$ & .856 \\
\hline $\mathrm{D} \times \mathrm{M}$ & .19 & .664 & $<.001$ & .05 & .819 & $<.001$ \\
\hline $\mathrm{D} \times \mathrm{AL}$ & 19.52 & $<.001$ & .075 & 20.15 & $<.001$ & .078 \\
\hline $\mathrm{D} \times \mathrm{IT}$ & 1.34 & .248 & .006 & 2.17 & .142 & .009 \\
\hline $\mathrm{M} \times \mathrm{AL}$ & .01 & .933 & $<.001$ & .13 & .720 & $<.001$ \\
\hline $\mathbf{M} \times \mathbf{I T}$ & 25.79 & $<.001$ & .097 & 12.46 & $<.001$ & .050 \\
\hline $\mathbf{A L} \times \mathbf{I T}$ & 123.12 & $<.001$ & .338 & 69.28 & $<.001$ & .225 \\
\hline $\mathrm{D} \times \mathrm{M} \times \mathrm{AL}$ & .52 & .472 & .002 & .53 & .469 & .002 \\
\hline $\mathrm{D} \times \mathrm{M} \times \mathrm{IT}$ & .29 & .590 & .001 & .10 & .754 & $<.001$ \\
\hline $\mathrm{D} \times \mathrm{AL} \times \mathrm{IT}$ & .84 & .362 & .003 & .91 & .340 & .004 \\
\hline $\mathbf{M} \times \mathbf{A L} \times \mathbf{I T}$ & 6.95 & .009 & .028 & 4.02 & .046 & .017 \\
\hline $\mathbf{D} \times \mathbf{M} \times \mathbf{A L} \times \mathbf{I T}$ & .01 & .912 & $<.001$ & .02 & .885 & $<.001$ \\
\hline Mindset Familiarity (MF) & - & - & - & 11.23 & $<.001$ & .045 \\
\hline Special Ed (SE) & - & - & - & .09 & .759 & $<.001$ \\
\hline $\mathrm{MF} \times \mathrm{AL}$ & - & - & - & .18 & .671 & $<.001$ \\
\hline $\mathrm{MF} \times \mathrm{IT}$ & - & - & - & 20.11 & $<.001$ & .078 \\
\hline $\mathrm{SE} \times \mathrm{AL}$ & - & - & - & 1.66 & .199 & .007 \\
\hline $\mathrm{SE} \times \mathrm{IT}$ & - & - & - & 2.72 & .101 & .011 \\
\hline $\mathrm{MF} \times \mathrm{AL} \times \mathrm{IT}$ & - & - & - & 1.97 & .162 & .008 \\
\hline $\mathrm{SE} \times \mathrm{AL} \times \mathrm{IT}$ & - & - & - & .22 & .640 & $<.001$ \\
\hline
\end{tabular}

Note: Two analyses (Model 1 and Model 2) are reported for each of the three mindset measures that were collected. Each mindset measure was included as the Mindset (M) variable in the analysis. Model $2(d f s=$ $1,238)$ included all variables from Model $1(d f s=1,241)$, with the addition of two covariates (Mindset Familiarity and Special Education Focus) and their corresponding interaction terms. Primary effects of interest are in bold. 


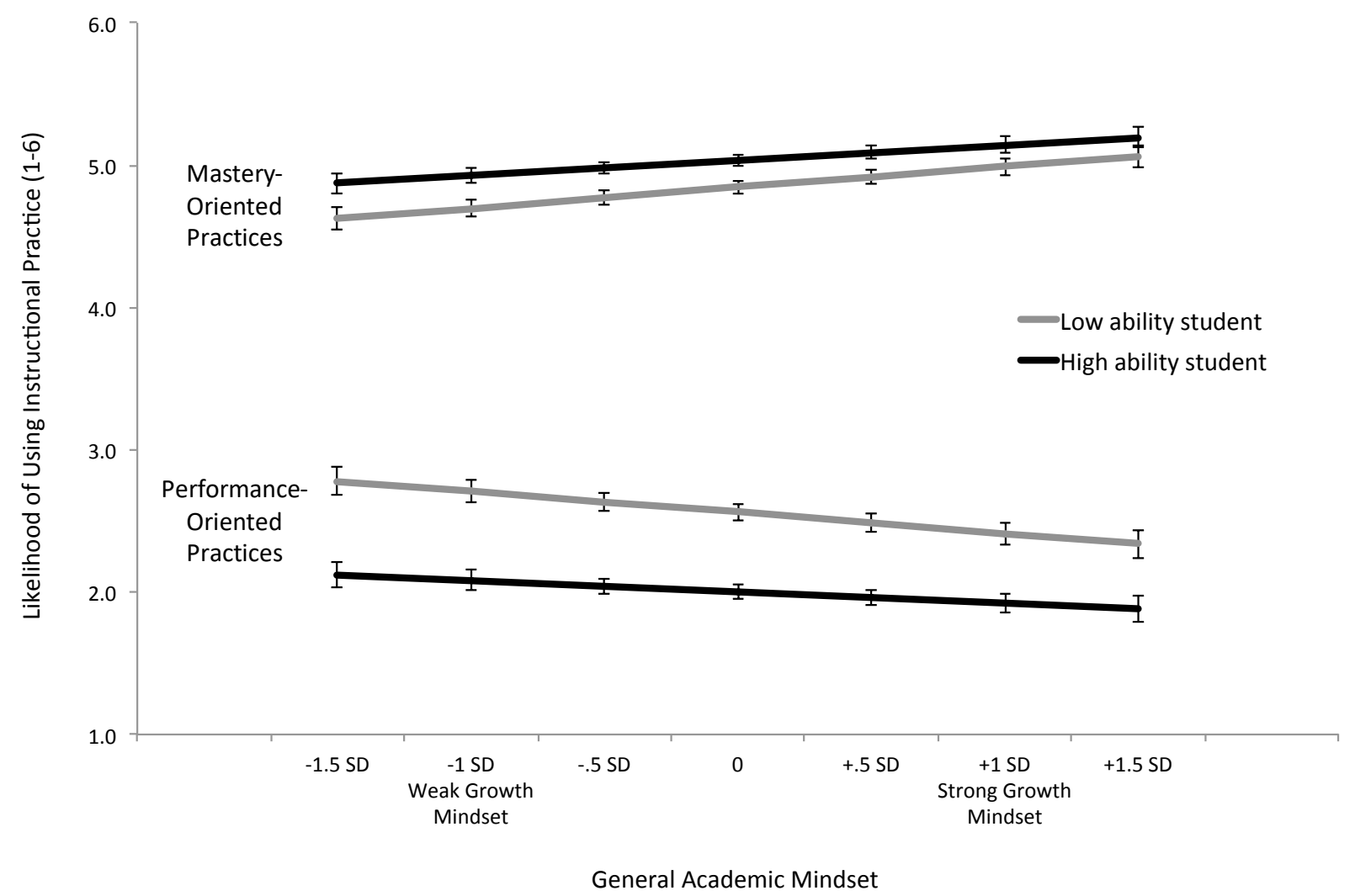

Figure 1. Significant growth mindset $\times$ ability level $\times$ instruction type interaction for Study 1 . Follow-up analyses were conducted at $1 S D$ above the mean of the general mindset measure for participants who exhibited a strong growth mindset, and $1 S D$ below the mean for participants who exhibited a weak growth mindset. $1 S D$ below the mean was slightly lower than the midpoint of the scale. The standardized values of the measure ranged from $-2.96 S D$ to $2.01 S D$. Data points represent estimated marginal means. Error bars represent one standard error. 


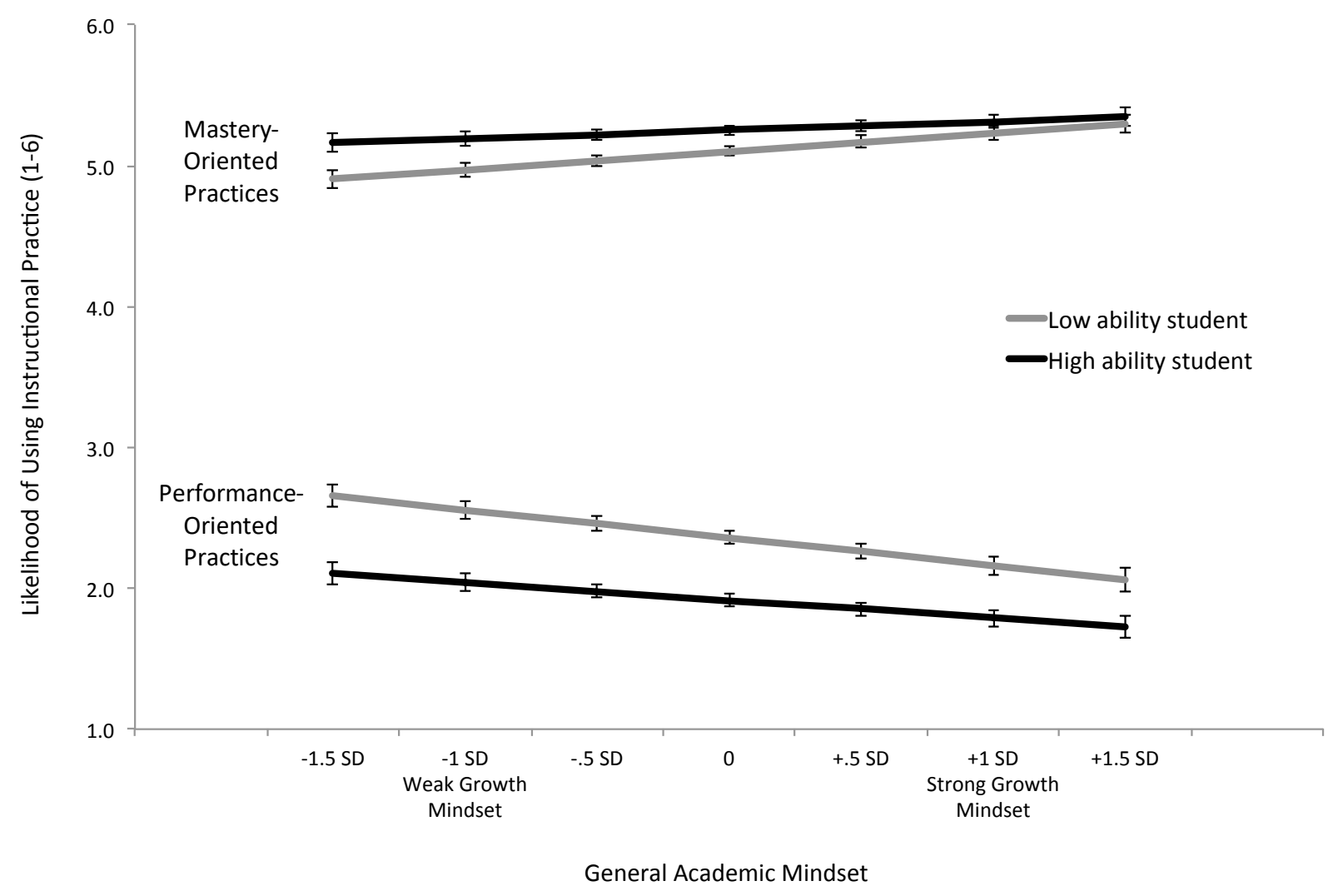

Figure 2. Significant growth mindset $\times$ ability level $\times$ instruction type interaction for Study 2 . Follow-up analyses were conducted at $1 S D$ above the mean of the general mindset measure for teachers who exhibited a strong growth mindset, and $1 S D$ below the mean for teachers who exhibited a weak growth mindset. $1 S D$ below the mean was roughly equivalent to the midpoint of the scale. The standardized values of the measure ranged from $-2.7 S D$ to $1.8 S D$. Data points represent estimated marginal means. Error bars represent one standard error. 


\section{Supplementary Materials}

This document reports various materials, procedures, analyses, and details pertaining to the project, some of which may be important for interpreting the main manuscript.

\section{Table of Contents}

1. Reliability Tests and Factor Analyses for the Instructional Practices Measures p. S1

2. Domain-Specific Mindsets and Differential Treatment p. S5

3. Order Effects for Instructional Practices Analyses in Study 2. p. S13

4. Additional Information about the Samples in Studies 1 and 2 p. S14

5. Supplemental Methods and Results for Study 2 p. S18

a. Additional Details on Analysis with General Mindsets and Covariates p. S18

b. Exploring the Effects of General Mindsets by Domain \& by Mindset Familiarity ..p. S18

c. Classroom Management Task p. S19

d. Gender Coding and Beliefs about Gender Differences in Ability. p. S23

e. Teacher Goal Orientations and Differential Treatment..... p. S24

6. Additional Studies Conducted p. S30

7. References p. S32

\section{Reliability Tests and Factor Analyses for the Instructional Practices Measure}

\section{Study 1}

Computing ordinal omega. As discussed in the main text, standard reliability analyses for each 5-item scale of the instructional practices measure yielded low Cronbach's alpha coefficients $(\alpha \mathrm{s}=.41-.56$ for the mastery subscales and $\alpha \mathrm{s}=.54-.64$ for the performance subscales). However, this may have been in part because Cronbach's alpha makes rigid assumptions that can introduce considerable downward bias when violated, especially when scales have a small number of items or are multidimensional (Dunn, Baguley, \& Brunsden, 2014; McNeish, 2018; Yang \& Green, 2011). The most relevant to our measure is the assumption of tau equivalence, or the requirement that each item on a scale contributes equally to 
the total scale score. For the tau equivalence assumption to be upheld, the standardized factor loadings for each item in an exploratory factor analysis (EFA) would need to be nearly identical to all other items on the scale. However, as shown in Table S1, this is not the case for our (or most) scales (see McNeish, 2018). This does not necessarily mean that the weaker loading items need to be removed, just that alpha underestimates true reliability, especially when the number of items is small (Green and Yang, 2009; McNeish, 2018). In order to provide a more accurate estimate of reliability, we computed omega, which does not assume tau equivalence, but can be interpreted in the same manner as alpha (see Kelley \& Pornprasertmanit, 2016; McNeish, 2018). Furthermore, because Pearson correlations (on which Cronbach's alpha coefficients are based) can severely underestimate the relationship between two Likert-type (ordinal) items that exhibit skewed response distributions, and because many of the items in our scales exhibited a high level of skew (44 of the 80 items had a skew $>|1|$, and 11 of these had a skew $>|2|$ ), we computed an ordinal version of omega $\left(\omega_{\text {ordinal }}\right)$ based on polychoric correlation matrices (see Gadermann, Guhn, \& Zumbo, 2012; McNeish, 2018). However, it should be noted that ordinal reliability coefficients "do not measure the reliability of the observed scores but rather constitute estimates of the hypothetical reliability for latent scale scores based on the sum of the continuous variables that are thought to underlie the observed discrete scores" (Garrido et al., in press, p. 6; see also, Chalmers, 2018).

Calculations for ordinal omega were based on standardized factor loadings from the EFAs described below, which were computed in R using the formula provided by McNeish 
(2018). The resulting coefficients were acceptable, with a mean of $\omega_{\text {ordinal }}=.65$ (range: .59-.74)

for the mastery subscales and $\omega_{\text {ordinal }}=.72$ (range: $.68-.77$ ) for the performance subscales. ${ }^{1}$

Table S1. Standardized loadings for two-factor solution averaged across all eight administrations of the instructional practices scale in Study 1.

\begin{tabular}{lcc}
\hline \multicolumn{1}{c}{ Item } & Factor 1 & Factor 2 \\
\hline $\begin{array}{l}\text { Mastery-oriented instructional practices } \\
\text { 1. Provide her with hints about how to solve the problem she is struggling } \\
\text { with without actually solving the problem for her. }\end{array}$ & - & -- \\
2. Explain the value and utility of the lesson and the assignment. & .30 & .47 \\
3. Ask her to explain her thinking behind her answers. & -- & .75 \\
4. Ask her challenging questions that will make her think critically about the & -- & .57 \\
material. & -- & .55 \\
5. Encourage her to keep working hard on the assignment. & & - \\
Performance-oriented instructional practices & .56 & -- \\
6. Offer her rewards and/or incentives for correct responses. & .60 & -- \\
7. Give her the solutions to the problems she is struggling with. &.- \\
8. Comfort her and reassure her that although she is not skilled in this specific \\
area, she is surely skilled in others.
\end{tabular}

Note. Loadings less than $|.3|$ are suppressed.

Exploratory factor analyses (EFAs). For each administration of our scale, we conducted an EFA using the Psych package in R (Revelle, 2017). In each analysis, we derived a non-iterated principal axes solution based on a polychoric correlation matrix (computed without continuity correction) and squared multiple correlations as the starting values on the diagonal. The number of factors was initially determined by Horn's Parallell Analysis (HPA; Horn, 1965),

\footnotetext{
${ }^{1}$ Note that, in addition to ordinal omega, we also computed ordinal alpha; these coefficients were generally higher than Cronbach's alpha, but lower than ordinal omega. We also computed ordinal omega total (see McNeish, 2018), which was generally higher than ordinal omega; however, not all items loaded onto the general factor in all analyses.
} 
which was conducted using the Psych package in R (Revelle, 2017) with polychoric correlations (without correction), principal components extraction, and the mean eigenvalue criterion (as recommended for skewed ordinal data by Garrido, Abad, \& Ponsoda, 2013). The analysis suggested that two factors should be extracted for four administrations of the scale (i.e., for five scenarios); for two of the remaining administrations it recommended three factors and for one administration it recommended four factors. In all cases, the third factor was fairly close to the threshold.

Because the scale was designed based on theoretical grounds to contain two subscales, we only extracted two factors in all cases. This was also consistent with how we conducted the primary analyses described in the manuscript, which were conducted before the EFA. For an initial set of analyses, a direct-oblimin rotation was applied. The correlation between the two factors was quite low on average (-.13, range: -.25 to -.02). Thus, to maximize parsimony, we report average standardized loadings from analyses utilizing a varimax rotation (see Table S1).

\section{Study 2}

Computing omega. As in Study 1, standard reliability analyses for each 5-item scale yielded low Cronbach's alpha coefficients $(\alpha \mathrm{s}=.53-.54$ for the mastery subscales and $\alpha \mathrm{s}=.55-$ .56 for the performance subscales). However, because many of the items in our scales exhibited a high level of skew (12 of the 20 items had a skew $>|1|$ and 4 of these had a skew $>|2|$ ), we again computed omega based on polychoric correlation matrices. The resulting coefficients were acceptable $\left(\omega_{\text {ordinal }}=.63-.69\right.$ for the mastery subscales and $\omega_{\text {ordinal }}=.69-.70$ for both of the performance subscales).

Exploratory factor analyses (EFAs). For each administration of our scale, we again conducted an EFA using the Psych package in R (Revelle, 2017). In each analysis, we derived a non-iterated principal axes solution based on a polychoric correlation matrix (computed without 
continuity correction) and squared multiple correlations as the starting values on the diagonal.

The number of factors was initially determined by Horn's Parallell Analysis (HPA; Horn, 1965), which was conducted using the psych package in R (Revelle, 2017) with polychoric correlations (without correction), principal components extraction, and the mean eigenvalue criterion (as recommended for skewed ordinal data by Garrido et al., 2013). The analysis suggested that three factors should be extracted for each administration of the scale (i.e., for the high ability and low ability scenarios), with the third factor being fairly close to threshold. However, because the scale was designed based on theoretical grounds to contain two subscales, we only extracted two factors. This was also consistent with how we conducted the primary analyses described in the manuscript, which were conducted before the EFA.

First, a direct-oblimin rotation was applied. The correlation between the two factors was quite low (-.08 for the low ability scale, -.13 for the high ability scale). To maximize parsimony, the model was re-fit with a varimax rotation. Rotated standardized loadings are presented for each scale in Table 2 of the main manuscript.

\section{Domain-Specific Mindsets and Differential Treatment}

In addition to the general mindset measure that is the focus on the primary analyses in this paper, both studies included domain-specific mindset measures. Specifically, prior research has shown that teachers and university professors are more likely to have a fixed mindset when it comes to math compared to other domains, such as those in the humanities or social sciences (Leslie et al., 2015; Patterson et al., 2016; see also Jonsson, Beach, Korp, \& Erlandson, 2012). This suggests that teachers may also be more likely to use performance-oriented practices and less likely to use mastery-oriented practices in math contexts compared to other academic settings. It also suggests that teachers may be more likely to engage in differential treatment of high and low ability students within the math domain. Although we made no firm predictions, 
we included measures of participants' domain-specific mindsets in both the math and verbal domains (to match the scenarios, which involved students struggling on either a math or verbal assignment) and tested for domain-specific differences in teachers' use of mastery- and performance-oriented instructional practices.

\section{Study 1}

Domain/child-specific mindset measures. In Study 1, domain-specific beliefs about children's math and verbal abilities were measured using revised versions of the Parents' Beliefs about Ability Fixedness (PBAF) scale (Muenks, Miele, Ramani, Stapleton, \& Rowe, 2015). This measure, which was presented after the measure of participants' general growth mindsets was originally designed to assesses parents' domain-specific beliefs about the fixedness of their children's abilities. Items were reworded to reflect participants' beliefs about children in general (e.g., "Children can always improve their math [verbal] ability, no matter how old they are," "Children's math [verbal] ability is innate and will never change") as opposed to about their own children, as in the original scale. Each scale contained the same six items, but referred to either children's math or verbal ability. The presentation order of the two scales was randomized across participants.

We explained to participants that we were interested in their beliefs about children's math [verbal] ability; and that, by math [verbal] ability we meant a child's ability to learn math-related [language-related] knowledge and skills, not his or her current math [language] skills.

Participants responded to the items using a 6-point Likert-type scale ( $1=$ "Strongly Disagree" to $6=$ "Strongly Agree"). Their scores for the math scale $\left(\alpha=.77, \omega_{\text {ordinal }}=.85\right)$ and verbal scale $(\alpha$ $=.80, \omega_{\text {ordinal }}=.85$ ) were computed in the same manner as the general mindset index (four items in each scale were reverse coded). One participant scored less than $3 S D$ below the mean of the 
index for the verbal domain (-3.2) but was included in all analyses. Also, after conducting the analyses, we realized that one participant was missing one rating from the math-specific scale; this participant's score for this scale was based on the mean of five out of six items.

\section{Results.}

Descriptive statistics. A descriptive analysis of participants' raw scores on math and verbal mindset measures revealed that, as with the general mindsets measure, mean scores $(M \mathrm{~s}=$ 4.78 and $4.37, S D \mathrm{~s}=.70$ and .79 , respectively) were significantly above the midpoint of the scale $(3.5 ; t \mathrm{~s}>14.43, p \mathrm{~s}<.001)$. In addition, over $93 \%$ of the individual scores on the math mindset measure and over $85 \%$ of the scores on the verbal measure were above the midpoint. These results indicate that, in general, participants tended to possess domain-specific growth mindsets to varying degrees.

With respect to the associations between mindset measures, we found that participants' general academic mindsets were moderately correlated with both their math-specific mindsets $(r$ $=.48, p<.001)$ and verbal-specific mindsets $(r=.43, p<.001)$, and that the two domain-specific mindsets measures were strongly correlated with each other $(r=.57, p<.001)$. Unexpectedly, and contrary to prior findings, we also found that participants exhibited a stronger growth mindset for math ability than for verbal ability, $t(173)=7.84, p<.001$.

\section{Association between domain-specific mindsets and self-reported instructional practices.}

To explore associations between domain-specific mindsets and participants' self-reported instructional practices, we utilized the same analytical approach as in our primary analyses except that we removed domain as a factor and conducted separate ANCOVAs for each domain. That is, we conducted one ANCOVA for the math scenarios in which math mindset served as the continuous covariate, and another ANCOVA for the language arts scenarios in which verbal mindset served as the covariate. The results (see Table S2) showed that all of the effects that 
were significant in the analysis that involved general mindsets were also significant in the analyses involving domain-specific mindsets, with the exceptions of the ability level $\times$ instruction type $\times$ mindset interactions $(p s>.388)$. That is, although the instruction type $\times$ mindset interactions appeared to be stronger in the present analyses than in the previous one $\left(\eta^{2}\right.$ 's $\left.>.111\right)$, they were not moderated by participants' perceptions of students' ability level.

It is worth noting that in the math domain, but not the language arts domain, participants with weaker growth mindsets appeared to strongly differentiate between high and low performing students in terms of performance-oriented practices. That is, participants with weaker math-specific growth mindsets (1 SD below the mean) reported being more likely to use performance-oriented practices with the low math ability students than with the high math ability students, $F(1,172)=122.31, p<.001, \eta^{2} \mathrm{p}=.416$. This was also the case for participants with stronger growth mindsets (1 SD above the mean), but to a lesser extent, $F(1,172)=63.53, p<$ $.001, \eta^{2} \mathrm{p}=.270$. As a result, the association between math-specific mindsets and differential treatment (i.e., the mindset $\times$ ability level interaction) for performance-oriented practices was significant, $F(1,172)=4.76, p=.031, \eta^{2}=.027$.

Table S2. Summary of ANCOVA Results for Self-Reported Teaching Practices from Analyses Involving the Domain/Child-Specific Mindset Measure.

\begin{tabular}{|c|c|c|c|c|c|c|}
\hline \multirow[b]{3}{*}{ Variable } & \multicolumn{6}{|c|}{ Domain/Child-Specific Mindset Measure } \\
\hline & \multicolumn{3}{|c|}{ Math } & \multicolumn{3}{|c|}{ Verbal } \\
\hline & $F$ & $p$ & $\eta_{\mathrm{p}}^{2}$ & $F$ & $p$ & $\eta^{2} \mathrm{p}$ \\
\hline Mindset (M) & .11 & .740 & $<.001$ & .01 & .913 & $<.001$ \\
\hline Ability Level (AL) & 58.12 & $<.001$ & .253 & 60.53 & $<.001$ & .260 \\
\hline Instruction Type (IT) & 1826.29 & $<.001$ & .914 & 1803.43 & $<.001$ & .913 \\
\hline $\mathrm{M} \times \mathrm{AL}$ & 7.01 & .009 & .039 & .82 & .368 & .005 \\
\hline $\mathbf{M} \times \mathbf{I T}$ & 21.64 & $<.001$ & .112 & 23.06 & $<.001$ & .118 \\
\hline $\mathbf{A L} \times \mathbf{I T}$ & 160.83 & $<.001$ & .483 & 159.99 & $<.001$ & .482 \\
\hline
\end{tabular}




\begin{tabular}{lllllll}
$\mathrm{M} \times \mathrm{AL} \times \mathrm{IT}$ & .75 & .388 & .004 & .08 & .773 & $<.001$ \\
\hline
\end{tabular}

Note: Separate analyses were conducted for the math and verbal domains. Each mindset measure was included as the Mindset (M) variable in the analysis. Primary effects of interest are in bold. $d f \mathrm{~s}=1,172$

However, the association between math-specific mindsets and differential treatment for mastery-oriented practices in a math context - though not significant, $F(1,172)=1.42, p=.253$, $\eta_{\mathrm{p}}^{2}=.008$ - was actually positive, in contrast to the association between general growth mindsets and differential treatment for mastery-oriented practices across contexts. This change in direction for mastery-oriented practices (which we also observed in the verbal domain) explains why the full three-way interaction (i.e., ability level $\times$ instruction type $\times$ math-specific mindset) was not significant.

\section{Study 2}

Domain/child- and field-specific mindset measures. As in Study 1, domain/childspecific beliefs about children's math and verbal abilities were measured using the revised PBAF scale (Muenks et al., 2015). After completing the general mindset measure, participants received the version of the scale corresponding to their domain condition (math: $\alpha=.76, \omega_{\text {ordinal }}=.89$; verbal: $\left.\alpha=.76, \omega_{\text {ordinal }}=.87\right)$. We constructed a single standardized index from these scores that varied by domain. Unlike in Study 1, the items of the scale were presented in a random order.

After completing the domain/child-specific mindset measure, participants also completed a 4-item field-specific ability scale (Leslie et al., 2015) assessing the extent to which they believed that innate ability versus effort and dedication is required to succeed in math- or humanities-related disciplines (e.g., "Being a top scholar of a math-related discipline requires a special aptitude that just can't be taught"; "When it comes to math-related disciplines, the most important factors for success are motivation and sustained effort; raw ability is secondary"). The four items, which were presented in a random order and which participants responded to using a 
6-point Likert-type scale (1= "Strongly Disagree" to 6 = "Strongly Agree"), were framed in terms of either math or humanities, depending on which domain condition participants were assigned to. For participants in each domain, we reverse-coded the two fixed mindset items and then computed the standardized average across all four items so that higher values indicated growth-oriented beliefs about ability (math: $\alpha=.77, \omega_{\text {ordinal }}=.79$; verbal: $\alpha=.73, \omega_{\text {ordinal }}=.76$ ). We then constructed a single standardized index from these scores that varied by domain. One participant scored less than $3 S D$ below the mean of this index (-3.2), but was included in all analyses.

\section{Results.}

Descriptive statistics. A descriptive analysis of teachers' raw scores on the measures of domain/child-specific mindsets and field-specific ability beliefs revealed that, as with their general mindsets, mean scores $(M \mathrm{~s}=5.21$ and $4.40, S D \mathrm{~s}=.55$ and .76 , respectively) were significantly above the midpoint of the scale $(3.5 ; t \mathrm{~s}>18.54, p \mathrm{~s}<.001)$. In addition, $100 \%$ of scores on the original domain-specific measure and over $83 \%$ of scores on the field-specific ability measure were above the midpoint. These results indicate that, in general, teachers tended to possess growth mindsets to varying degrees.

With respect to the associations between mindset measures, we found that teachers' general academic mindsets were moderately correlated with their domain-specific mindsets $(r=$ $.40, p<.001)$ and strongly correlated with their field-specific ability beliefs $(r=.64, p<.001)$, and that domain-specific mindsets were moderately correlated with field-specific ability beliefs $(r=.41, p<.001)$. In addition, to examine differences in beliefs across domains, we conducted two between-samples t-tests. The first test showed that, consistent with Study 1, teachers exhibited a stronger domain-specific growth mindset with regard to students' math abilities $(M=$ $5.28, S D=.50)$ than with regard to their verbal abilities $(M=5.14, S E=.58), t(243)=2.01, p=$ 
$.046, d=.26$. In contrast, there was no difference in field-specific ability beliefs across domains, $t(243)=.76, p=.448, d=.10$.

Table S3. Summary of ANCOVA Results for Self-Reported Teaching Practices from Analyses Involving Two Different Mindset Measures.

\begin{tabular}{|c|c|c|c|c|c|c|c|c|}
\hline \multirow[b]{3}{*}{ Variable } & \multicolumn{4}{|c|}{ Domain/Child-Specific Mindset } & \multicolumn{4}{|c|}{ Field-Specific Mindset } \\
\hline & \multicolumn{2}{|c|}{ Model 1} & \multicolumn{2}{|c|}{ Model 2} & \multicolumn{2}{|c|}{ Model 1} & \multicolumn{2}{|c|}{ Model 2} \\
\hline & $F$ & $\eta^{2} p$ & $F$ & $\eta^{2} p$ & $F$ & $\eta^{2} p$ & $F$ & $\eta^{2} p$ \\
\hline Domain (D) & 2.58 & .011 & $2.73^{\dagger}$ & .011 & 1.75 & .007 & 2.27 & .009 \\
\hline Mindset (M) & 1.64 & .007 & .17 & $<.001$ & $11.64^{* * *}$ & .046 & $5.66^{*}$ & .023 \\
\hline Ability Level (AL) & $42.95^{* * *}$ & .151 & $19.89^{* * *}$ & .077 & $43.34^{* * * *}$ & .152 & $17.64^{* * *}$ & .069 \\
\hline Instruction Type (IT) & $3645.20^{* * *}$ & .938 & $1531.64^{* * *}$ & .866 & $3862.45^{* * *}$ & .941 & $1546.01^{* * *}$ & .867 \\
\hline $\mathrm{D} \times \mathrm{M}$ & 1.35 & .006 & .76 & .003 & 1.36 & .006 & 1.51 & .006 \\
\hline $\mathrm{D} \times \mathrm{AL}$ & $18.83^{* * *}$ & .072 & $19.51^{* * *}$ & .076 & $19.30^{* * *}$ & .074 & $19.68^{* * *}$ & .076 \\
\hline $\mathrm{D} \times \mathrm{IT}$ & .46 & .002 & 1.08 & .004 & $3.23^{\dagger}$ & .013 & $3.87^{\dagger}$ & .016 \\
\hline $\mathrm{M} \times \mathrm{AL}$ & .11 & $<.001$ & .03 & $<.001$ & .33 & .001 & .68 & .003 \\
\hline $\mathbf{M} \times \mathbf{I T}$ & $34.53^{* * *}$ & .125 & $26.31^{* * *}$ & .100 & $47.46^{* * *}$ & .164 & $28.68^{* * *}$ & .108 \\
\hline $\mathbf{A L} \times \mathbf{I T}$ & $127.21^{* * *}$ & .345 & $\mathbf{7 6 . 8 1}^{* * *}$ & .244 & $122.77^{* * *}$ & .337 & $72.22^{* * *}$ & .233 \\
\hline $\mathrm{D} \times \mathrm{M} \times \mathrm{AL}$ & .01 & $<.001$ & .002 & $<.001$ & .66 & .003 & .48 & .002 \\
\hline $\mathrm{D} \times \mathrm{M} \times \mathrm{IT}$ & $6.70^{*}$ & .027 & $6.78^{* *}$ & .028 & .01 & $<.001$ & .18 & $<.001$ \\
\hline $\mathrm{D} \times \mathrm{AL} \times \mathrm{IT}$ & 1.29 & .005 & 1.36 & .006 & .47 & .002 & .60 & .003 \\
\hline $\mathbf{M} \times \mathbf{A L} \times \mathbf{I T}$ & $7.94^{* *}$ & .032 & $5.83^{*}$ & .024 & $4.58^{*}$ & .019 & 2.25 & .009 \\
\hline $\mathbf{D} \times \mathbf{M} \times \mathbf{A L} \times \mathbf{I T}$ & 2.59 & .011 & 2.44 & .010 & $5.96^{*}$ & .024 & $6.07^{*}$ & .025 \\
\hline Mindset Fam (MF) & - & - & $11.11^{* * *}$ & .045 & - & - & $6.99^{* *}$ & .029 \\
\hline Special Ed (SE) & - & - & .05 & $<.001$ & - & - & .03 & $<.001$ \\
\hline $\mathrm{MF} \times \mathrm{AL}$ & - & - & .09 & $<.001$ & - & - & .33 & .001 \\
\hline $\mathrm{MF} \times \mathrm{IT}$ & - & - & $25.25^{* * *}$ & .096 & - & - & $18.10^{* * *}$ & .071 \\
\hline $\mathrm{SE} \times \mathrm{AL}$ & - & - & 1.67 & .007 & - & - & 1.72 & .007 \\
\hline $\mathrm{SE} \times \mathrm{IT}$ & - & - & $2.99^{\dagger}$ & .012 & - & - & 2.55 & .011 \\
\hline $\mathrm{MF} \times \mathrm{AL} \times \mathrm{IT}$ & - & - & $2.77^{\dagger}$ & .012 & - & - & $2.89^{\dagger}$ & .012 \\
\hline $\mathrm{SE} \times \mathrm{AL} \times \mathrm{IT}$ & - & - & .21 & $<.001$ & - & - & .05 & $<.001$ \\
\hline
\end{tabular}

Note: Two analyses (Model 1 and Model 2) are reported for each of the mindset measures. Each mindset measure was included as the Mindset $(\mathrm{M})$ variable in the analysis. Model $2(d f s=1,238)$ included all variables from Model 1 $\left(d f_{s}=1,241\right)$, with the addition of two covariates (Mindset Familiarity and Special Education Focus) and their corresponding interaction terms. Primary effects of interest are in bold.

${ }^{\dagger} p<.10 .{ }^{*} p<.05 .{ }^{* *} p<.01 .{ }^{* * *} p<.001$

\section{Association between domain/child-specific mindsets and self-reported instructional}

practices. To explore the association between domain/child-specific mindsets and teachers' self- 
reported instructional practices, we utilized the same analytical approach as in Study 1 (see Table S3 for full results). The results showed that all of the effects that were significant in the analysis that involved general mindsets were also significant in the present analysis, including the mindset $\times$ ability level $\times$ instruction type interaction $(p=.005)$.

Although the three-way interaction was not quite qualified by a significant four-way interaction involving domain, $F(1,241)=2.59, p=.109, \eta^{2}{ }_{p}=.011$, we decided to examine the association between the association between domain/child-specific mindsets and differential treatment separately for the math and language arts domains. The association was significant for math, $F(1,241)=8.76, p=.003, \eta^{2}=.035$, but not language arts, $F(1,241)=.83, p=.364, \eta^{2}$ p $=.003$. The four-way interaction also qualified a lower-order effect of domain that was not significant in the analysis involving general mindsets (i.e., the domain $\times$ mindset $\times$ instruction type interaction, $p=.010)$.

An additional analysis that included mindset familiarity and special education focus as covariates yielded the same effects. In addition, the main effects for domain and mindset familiarity, as well as the mindset familiarity $\times$ instruction type, special education focus $\times$ instruction type, and mindset familiarity $\times$ ability level $\times$ instruction type interactions, were either significant or marginally significant.

To explore the association between teachers' field-specific ability beliefs and their selfreported instructional practices, we again utilized the analytical approach described above. The results showed that all of the effects that were significant in the analysis involving general mindsets were also significant in the present analysis, including the mindset $\times$ ability level $\times$ instruction type interaction $(p=.033)$. Furthermore, the four-way interaction involving domain was significant in the present analysis, $F(1,241)=5.96, p=.015, \eta_{p}^{2}=.024$. Follow-up analyses revealed that the association between domain-specific mindsets and differential treatment of low 
and high ability students was significant in the math domain, $F(1,241)=11.12, p<.001, \eta^{2}{ }_{p}=$ .044 , but not in the language arts domain, $F(1,241)=.04, p=.835, \eta_{\mathrm{p}}^{2}<.001$. The four-way interaction also qualified a significant main effect of field-specific ability beliefs $(p=.001)$ and a marginally significant domain $\times$ instruction type interaction $(p=.07)$, which were not present in the previous analysis of domain-general mindsets.

An additional analysis that included mindset familiarity and special education focus as covariates yielded the same effects, with the exception that the mindset $\times$ ability level $\times$ instruction type interaction was no longer significant $(p=.135)$, though the four-way interaction involving domain remained significant $(p=.014)$. In addition, the main effect of mindset familiarity, as well as the mindset familiarity $\times$ instruction type and mindset familiarity $\times$ ability level $\times$ instruction type interactions were at least marginally. However, the special education focus $\times$ instruction type interaction was not significant in this case $(p=.112)$. Additional followup analyses regarding the ANCOVAs described in this section are available upon request. For a discussion of the results involving domain/child-specific and field-specific mindsets, contact the first author.

\section{Order Effects for Instructional Practices Analyses in Study 2}

We conducted additional analyses to determine whether scenario order (i.e., whether teachers were asked to think about a high or low ability student first) moderated any of the primary effects of interest by adding order as a variable (and all corresponding interaction terms) to the three ANCOVA analyses that included either general mindsets, domain-specific mindsets, or field-specific ability beliefs as the continuous predictor (but did not include mindset familiarity or special education focus as additional covariates). We found that for the analyses involving general mindsets and field-specific ability beliefs, there were significant instruction type $\times$ mindset $\times$ order interactions $(p s<.040)$, such that the instruction type $\times$ mindset 
interactions were stronger when teachers completed the high ability scenario first (though these interactions were at least marginally significant for both orders). The instruction type $\times$ mindset $\times$ order interaction was not significant for the domain-specific mindset analysis $(p=.922)$. In addition, for the general mindset measure, we found a marginally significant ability level $\times$ instruction type $\times$ mindset $\times$ order interaction $(p=.060)$, such that the three-way ability level $\times$ instruction type $\times$ mindset interaction (representing differential treatment) was significant when teachers completed the high ability scenario first $(p<.001)$, but not when they completed the low ability scenario first $(p=.378)$. The ability level $\times$ instruction type $\times$ mindset $\times$ order interactions were not significant in the analyses involving domain-specific mindsets $(p=.931)$ or field-specific ability beliefs $(p=.234)$. Full results for these analyses, which included other significant order effects, are available on request.

The presence of order effects may suggest that the effects of interest are partly dependent on how teachers contrast two students within the same context or setting. As a result, it is worth considering the role that social comparison plays in the observed relation between growth mindsets and differential treatment. It is possible that teachers with weaker growth mindsets only become more likely to use performance-oriented practices with low ability students (and less likely to use mastery-oriented practices) after they have interacted with students they perceive to be high in ability. That is, perhaps only when these teachers are actively aware of what a high ability student is capable of achieving do they think about the inherent limitations of low ability students. However, these findings are preliminary and future research should explore whether the effects of teachers' growth mindsets on their differential treatment of students are most likely to emerge in classroom settings involving multiple students of varying ability levels and least likely to occur in one-one-one settings, such as private tutoring.

\section{Additional Information about the Samples in Studies 1 and 2}




\section{Study 1}

As explained in the manuscript, 12 participants were excluded from the reported analyses because either they did not finish the study $(N=2)$, they were missing one or two responses for the domain-specific mindset measures $(N=9)$, or they exhibited no variability in their responses $(N=1)$. These exclusions criteria were developed when the construct of domain-specific mindsets (now reported here in the supplementary materials) was still a central construct. Note that some preliminary analyses of mindset measures and the task described in Footnote \#3 of the main text were conducted prior to applying these criteria.

\section{Study 2}

As explained in the main text, the recruitment emails that were sent to the list of alumni stated that the individual was invited to participate if he/she was "currently working as an elementary school teacher." Participants who clicked on the personalized link in the email were taken to an online consent form. But, before viewing the consent form, they had to respond to the following question: “Are you currently employed as an elementary school teacher $\underline{\text { or }}$ are you currently majoring in elementary education at [name of school]'? Though note that the recruitment emails during this period went out to alumni of the elementary education programs at the school and all but one participant specified that they had a degree from the university. Only individuals who answered "yes" to the question and then consented to participate were directed to the online survey.

As also explained in the main text, 122 teachers were excluded from the main analyses because they either failed to complete the study $(N=110)$, they were missing data central to the main dependent measure $(N=11)$, or were missing an excessive amount of data $(N=1)$. Specifically, 10 of the 11 participants wrote only a couple of words or nothing in response to one (or both) of our requests to write a brief description of a high [low] ability student and an 
explanation of why they considered him/her to have a high [low] level of math [verbal] ability. Another participant was missing instructional practices ratings for one of the scenarios. For the one participant who was excluded because of excessive missing data, much of this data was for tasks or measures that were not the focus of our paper - however, our concern was that the participant did not complete the other parts of the study with appropriate focus.

As explained in Footnote \#7 of the main text, an additional 11 participants completed a preliminary version of the survey that had at least one minor differences from the final versionspecifically, participants were not asked about their familiarity with growth mindsets (i.e., the naïveté check). There may have been some other unaccounted-for differences. Also note that at least one person started this preliminary version but did not finish. Data from the 11 participants were not analyzed. Five of the 11 participants responded to emails that we initially sent to a subset of 100 individuals from the list of 3,412 alumni referred to in the main manuscript (some participants from our final sample may have responded to these emails after the survey was changed); the other six were recruited from a separate list of 49 alumni.

Previously, analyses were conducted with a more stringent filter $(N=228)$ that was incorrectly/inconsistently applied. Analyses reported in the paper were conducted after the filter was revised. Also note that a disproportionate number (9 out 12) of the participants missing excessive data were in the verbal domain condition, such the final number of participants in the math and verbal conditions was 126 and 119, respectively.

After conducting the analyses reported in the main text, we identified three participants whose descriptions seemed to indicate that they did not seem to focus on a low or high ability student in the appropriate domain. One participant seemed to indicate that they had not encountered a low ability student, before having their response cut off by the timer. Another participant indicate that they work solely in language arts and thus seemed to suggest that they 
could not think of low and high ability students in the math domain. A third teacher indicated that they do not work with high ability math students and also did not indicate the grade of a particular high ability student (as requested). We conducted two additional analyses with these three participants excluded $(N=242)$ that mirrored the primary Study 2 analyses reported in the main manuscript. These analyses showed that the primary mindset $\times$ ability level $\times$ instruction type interaction was significant, both without the mindset familiarity and special education covariates, $F(1,238)=7.41, p=.007, \eta^{2} \mathrm{p}=.030$, and when these covariates were included, $F(1$, $235)=4.46, p=.036, \eta_{p}^{2}=.019$. In fact, the effect sizes of the interaction were slightly larger in these analyses than in the original analyses.

Note that in addition to these three participants, there were a number of participants who provided somewhat ambiguous descriptions of students, such that we could not determine whether they were thinking about the appropriate domain or whether they were thinking about a single student (i.e., some participants seemed to refer to low or high ability students in general). Furthermore, a number of participants described particular students as having a learning disability or some other condition, such as autism or Down syndrome.

The text entry boxes that participants used to enter their student descriptions were configured to appear for two minutes before the survey automatically advanced participants to the next screen. There were a few participants for whom one or both of the text boxes were recorded as appearing for substantially less than two minutes. There were also some participants for whom one or both of the text boxes appeared for a longer amount of time.

Also note that when answering the open-ended questions about their experience with the study (toward the end of the survey), two of the excluded participants provided an explanation for why they missed a response. In addition, two participants who were included in the study 
mentioned that they didn't get to finish discussing one of the students due to the two-minute time limit.

Finally, in addition to the demographic questions described in the main manuscript, a number of additional demographics questions (about the participants and their teaching experience) were included. For a full description of the demographic survey, contact the first author.

\section{Supplemental Methods and Results for Study 2}

Here, we present additional methods and results pertaining to Study 2. While these are not central to our main findings, we feel that they may be helpful to consider for future research investigating the relationships between mindsets, ability perceptions, and teacher behavior.

\section{a. Additional Simple Effects for Analysis Including General Mindsets, Familiarity with Dweck's Research, and Special Education Focus}

We conducted additional simple effects analyses to examine the associations between mindsets and instructional practices separately for the low and high ability students when controlling for familiarity with Dweck's research and special education focus. The results showed that the positive association between growth mindsets and mastery-oriented practices was significant for low ability students, $F(1,238)=9.61, p=.002, \eta^{2}=.039$, but only marginal for high ability students, $F(1,238)=3.62, p=.058, \eta^{2}{ }_{p}=.015$. Similarly, the negative association between mindsets and performance-oriented practices was significant for low ability students, $F(1,238)=6.54, p=.011, \eta^{2} \mathrm{p}=.027$, but not for high ability students, $F(1,238)=$ $1.56, p=.212, \eta_{\mathrm{p}}^{2}=.007$

\section{b. Exploring the Effects of General Mindsets by Domain and by Mindset Familiarity}

Although the general growth mindset $\times$ ability level $\times$ instruction type interaction was not moderated by domain, we conducted additional analyses that estimated this effect for each 
domain. The purpose of doing so was to better understand the domain related effects found with the other mindset measures. The analyses revealed that the association between domain-specific mindsets and differential treatment of low and high ability students was significant in the language arts domain, $F(1,241)=4.20, p=.041, \eta^{2}=.017$, and marginally significant in the math domain, $F(1,241)=2.89, p=.090, \eta^{2}{ }_{p}=.012$.

For the analyses with additional covariates (i.e., mindset familiarity and special education focus) that we reported in the main manuscript, our primary concern was controlling for potential third variables that could account for the association between mindsets and differential treatment. In addition, we conducted an analysis that examined whether mindset familiarity moderated the effects of mindsets on differential treatment. The relevant four-way interaction (mindset $\times$ ability level $\mathrm{x}$ instruction type $\mathrm{x}$ mindset familiarity) representing the moderation effect was not significant, $F(1,237)=.13, p=.721, \eta^{2}=.001$, and the primary interaction of interest (mindset $\times$ ability level $\mathrm{x}$ instruction type) remained significant, $F(1,237)=4.13, p=.043, \eta^{2} \mathrm{p}=.017$. When estimating the interaction separately for those who reported being familiar with mindsets and those who did not (based on the full model), we found similar sized effects, $F \mathrm{~s}=2.39$ and $1.78, p s=.123$ and $.184, \eta_{\mathrm{ps}}^{2}=.010$ and .007 .

\section{c. Classroom Management Task}

Rationale and Materials. We attempted to provide additional evidence for the relation between teachers' academic mindsets and their differential treatment of high and low ability students by introducing three additional measures of classroom teaching behavior.

Two of the measures involved having teachers imagine that they were teaching a class of 24 students that was divided into three equally-sized ability groups (low, average, and high) that were working on the same math [language arts] assignment. They were then asked to (1) indicate the order in which they would choose to help the groups during the 45 -minute class session $\left(1^{\text {st }}\right.$ 
to $3^{\text {rd }}$ ) and (2) specify how much time (in minutes) they would allot to helping each group, such that the total time spent helping three groups equaled 45 minutes. Because teachers with weaker growth mindsets (or more fixed mindsets) may believe that high ability students are likely to benefit from their instruction to a greater extent than low ability students, they may be more willing than teachers with stronger growth mindsets to prioritize working with high ability students. A final measure of differential treatment (included in one of the demographic questionnaires) asked teachers to (3) rate how much they favored the practice of ability grouping in elementary school classrooms ( 1 = "Strongly Oppose" to $6=$ "Strongly Favor"). To the extent that breaking a class into ability groups facilitates differential treatment, we might expect teachers with a weak growth mindset to be more in favor of this practice than teachers with a strong growth mindset.

\section{Results}

Associations between teachers' mindsets and helping order. Because of a problem with the administration of the helping order question, 32 participants were missing data for this item. Specifically, these participants chose the default order that appeared in the program as their preferred order, which resulted in the program not registering a response. As a result we conducted two sets of analyses for this item. The first set excluded participants with missing data on this measure and the second set imputed the default order to these participants.

To examine how teachers ranked the three ability groups in terms of the order in which they would help them, we initially conducted a repeated measures ANOVA. The results showed a significant effect of ability level across domains, $F(1.72,364.15)=31.52, p<.001, \eta^{2}{ }_{p}=.129$ (Huynh-Feldt corrected), such that teachers were more likely to work with the low ability group $(M=1.59, S D=.71)$ before either the average ability group $(M=2.24, S D=.65)$ or high ability group $(M=2.17, S D=.91), p s<.001$. There was no difference in mean ranking between the 
average and high ability groups, $p=.436$. An additional analysis that included the imputed data revealed the same pattern of results.

Next, to test the association between teachers' mindsets and the order in which they would help the different ability groups in their class, we subtracted the rank of the high ability group (1st, 2nd, or 3rd) from the rank for the low ability group, such that positive numbers indicated a preference for helping the high ability group before the low ability group. We then conducted a set of ANCOVAs with this difference score as the dependent measure, domain as a between-subjects factor, and one of the mindset measures as the continuous covariate predictor.

Results from the analyses involving the general mindset measure and the measure of field-specific ability beliefs were similar. In both cases, the only effect that was significant was the domain $\times$ mindset interaction, $F(1,209) \mathrm{s}>6.10, p \mathrm{~s}<.015, \eta^{2} \mathrm{p}_{\mathrm{s}}>.028$. Although, on average, teachers said they would work with the low ability group before the high ability group in both domains, teachers with weaker general growth mindsets (or weaker growth-oriented beliefs about math as a field) did not, when it came to the math domain, rank the high ability group as far behind the low ability group as did teachers with stronger growth mindset ( $p$ s $<$ .035). This pattern was reversed for teachers in the language arts condition (i.e., teachers with weaker growth mindsets ranked the high ability group farther behind the low ability group), although the effects were not significant $(p s>.166)$. When we conducted a second set of analyses with the imputed data, we found similar effects. The interaction was significant for both mindset measures $(p s<.007)$ and the simple effects for these measures were at least marginally significant in the math domain $(p s<.060)$. Furthermore, the reversal in the verbal domain was marginally significant in these analyses $(p \mathrm{~s}<.079)$.

Interestingly, when we conducted a similar set of analyses for the domain/child-specific mindset measure, we found only a significant main effect of mindset, $F(1,209)=4.03, p=.046$, 
$\eta_{p}^{2}=.019$ (this effect was marginal when examining the imputed data), such that teachers with weaker domain-specific growth mindsets did not rank the high ability group as far behind the low ability group as did teachers with a strong growth mindset, across both domains. Finally, an additional set of analyses for all three mindset measures was conducted with the addition of the mindset familiarity and special education focus as covariates (but without imputation). These analyses yielded similar patterns of results to the analyses without the extra covariates.

Associations between teachers' mindsets and time allocation. Nine participants provided times for the three groups that did not add up to 45 minutes. Data from these participants were excluded from the following analyses. Two participants commented toward the end of the study that they had accidentally swapped the times they allocated to the low and high ability groups. These times were manually corrected for the final analyses.

To examine how teachers allocated class time to the three ability groups, we initially conducted a repeated measures ANOVA. The results showed a significant effect of ability level across domains, $F(1.45,353.49)=594.26, p<.001, \eta_{p}^{2}=.709$ (Huynh-Feldt corrected), such that teachers reported that they would spend more time with the low ability group $(M=19.67 \mathrm{~m}$, $S D=3.17)$ than with the average ability group $(M=14.47 \mathrm{~m}, S D=1.85)$ or high ability group $(M=10.59, S D=2.57), p s<.001$. The difference between the average and high ability groups was also significant, $p<.001$.

Next, to examine the association between teachers' mindsets and their differential allocation of time to the low and high ability groups, we subtracted the time for the low ability group from the time for the high ability group, such that positive numbers indicated a preference for spending more time with the high ability group than the low ability group. The three analyses involving the three different mindset measures yielded no significant effects. Additional analyses 
that included mindset familiarity and special education focus as covariates also yielded no significant effects.

\section{Associations between teachers' mindsets and their preferences for ability grouping.}

Overall, teachers favored ability grouping as a practice in elementary school classrooms $(M=$ $3.90, S D=1.08)$; this mean was significantly higher than the midpoint of the scale $(3.5), t(244)=$ $5.79, p<.001$. However, a series of ANCOVAs with domain as a between-participant factor, showed that level of favorability was negatively associated with each of the three mindset measures, $F \mathrm{~s}>8.45, p \mathrm{~s}<.004, \eta^{2} \mathrm{p}^{\prime}>.033$. That is, the stronger teachers' growth mindsets were, the less likely they were to favor ability grouping. In all three cases, this association was qualified by a marginally significant domain $\times$ mindset interaction, $F \mathrm{~s}>2.78, p \mathrm{~s}<.097, \eta^{2}$ 's $=$ .011. In general, teachers with stronger growth mindsets were less likely than teachers with weaker growth mindsets to favor ability grouping as a practice when they were in the language arts condition $(p s<.001$; though this particular question did not ask them about ability grouping within a particular domain). This was not the case in the math condition, where there was no association between favorability and our measures of general or math-specific growth mindsets ( $p$ s $>$.327). There was, however, a significant negative association between favorability and field-specific ability beliefs in this domain $(p=.036)$, but this association was weaker than the corresponding association in the language arts domain. Additional analyses that included mindset familiarity and special education focus as covariates yielded a similar pattern of marginal domain $\times$ mindset interactions. For a discussion of the results involving the classroom management measures, contact the first author.

\section{d. Gender Coding and Beliefs about Gender Differences in Ability}

To examine differences in teachers' treatment of low and high ability students by gender, we coded teachers descriptions of the students they were asked to think about in terms of 
gendered language (e.g., masculine vs. feminine pronouns). For many responses, the gender of the student in question could not be determined. For analyses involving student gender variables, contact the first author.

In addition, after completing the field-specific mindset measure, participants completed a 4-item measure of their beliefs about gender differences in ability within math- or humanitiesrelated fields (depending on the domain condition). A sample items is "Are the most talented students in humanities-related fields more likely to be boys or girls?" Analyses involving this measure are available upon request.

\section{e. Teacher Goal Orientations}

As outlined in the General Discussion of the main manuscript, another explanation for the association between teachers' mindsets and their differential treatment of low and high ability students pertains to what teachers believe about the malleability of their own intelligence, rather than the intelligence of their students. Specifically, teachers who believe that they themselves have a fixed amount of intellectual ability may be particularly concerned with demonstrating that this amount is high enough for them to be successful as a teacher-just as students with fixed mindsets tend to be concerned with demonstrating that they are smart enough to do well in school (Haimovitz, Wormington, \& Corpus, 2011; Mueller \& Dweck, 1998; Stipek \& Gralinski, 1996). Consequently, they may adopt performance goals aimed at maximizing positive outcomes that indicate high teaching ability or minimizing negative outcomes that indicate low teaching ability, such as high or low student test scores (see Butler, 2007). These goals may, in turn, be positively associated with their use of performance-oriented instructional practices (and thus negatively associated with their use of mastery-oriented practices) specifically with low ability students, as it is these students who are in danger of bringing down the class average. 
To test this possibility, we examined a measure of teacher goal orientations that participants in Study 2 had completed after the measure of beliefs about gender differences in ability. Specifically, we examined the relations between these orientations, teacher mindsets, and self-reported instructional practices.

Measure. Teachers' goal orientations were assessed using Butler's (2012) 20-item scale designed to measure five types of goals related to their instructional practice; mastery goals (e.g. “I would feel I had a particularly successful day if a student's question made me think differently about the topic I was teaching"; $\alpha=.73, \omega_{\text {ordinal }}=.82$ ), ability-approach goals (e.g. "I would feel 1 had a particularly successful day if, in a staff meeting, my lesson plans were superior to those of other teachers"; $\alpha=.80, \omega_{\text {ordinal }}=.82$ ), ability-avoidance goals (e.g. "I would feel that I had a particularly successful day if students didn't embarrass me by asking questions I didn't know how to answer"; $\left.\alpha=.65, \omega_{\text {ordinal }}=.71\right)$, work-avoidance goals (e.g. "I feel that I had a good and successful day when I don't have to grade or go over papers/tests/worksheets"; $\alpha=.68, \omega_{\text {ordinal }}=$ .79), and relational goals (e.g., "More than anything, I try to build and develop my relationship with students"; $\alpha=.82, \omega=.85)$. The two types of ability goals can also be thought of as performance goal orientations. Participants were asked to indicate the extent to which they agreed with each item on a 6-point Likert scale (1= "Strongly Disagree" to $6=$ "Strongly Agree”). The items were presented in a random order.

\section{Results.}

Association between teachers' goal orientations, mindsets, and self-reported instructional practices. One participant was missing a response for two of the goal orientation subscales and was excluded from analyses. 
As shown in Table S4, teachers' general and domain-specific mindsets were significantly correlated with many of their goal orientations. In general, teachers' growth mindsets were negatively associated with their ability and work avoidance goals, but positively associated with their mastery goals (and, in one case, with their relational goals).

Table S4. Zero-order correlations between all mindset measures and teacher goal orientations in Study 2.

\begin{tabular}{|c|c|c|c|c|c|c|c|c|}
\hline & 1 & 2 & 3 & 4 & 5 & 6 & 7 & 8 \\
\hline \multicolumn{9}{|l|}{ Mindset Measures } \\
\hline 1. General & -- & & & & & & & \\
\hline 2. Domain-Specific & $.40^{* *}$ & -- & & & & & & \\
\hline 3. Field-Specific & $.64^{* *}$ & $.41^{* *}$ & -- & & & & & \\
\hline \multicolumn{9}{|l|}{ Goal Orientations } \\
\hline 4. Mastery & $.17^{* *}$ & $.27^{* *}$ & $.32^{* *}$ & -- & & & & \\
\hline 5. Ability-Approach & $-.17^{* *}$ & -.08 & $-.19^{* *}$ & $-.13^{*}$ & -- & & & \\
\hline 6. Ability-Avoidance & $-.30^{* *}$ & $-.29^{* *}$ & $-.37^{* *}$ & $-.29^{* *}$ & $.39^{* *}$ & -- & & \\
\hline 7. Relational & .07 & .07 & $.17^{* *}$ & $.28^{* *}$ & .10 & .07 & -- & \\
\hline 8. Work-Avoidance & -.10 & $-.20^{* *}$ & -.12 & $-.25^{* *}$ & $.24^{* *}$ & $.47^{* *}$ & .01 & -- \\
\hline
\end{tabular}

${ }^{*} p<.05, * * p<.01, \mathrm{~N}=245$ for correlations between mindset measures, $\mathrm{N}=244$ for all other correlations

To explore associations between teachers' goal orientations and their self-reported instructional practices, we conducted a series of ANCOVAs (as above), each with a different goal orientation as the continuous covariate predictor. To simplify our description of the results, we report only whether the key interactions of interest were significant. With respect to whether teachers' goal orientations predict their use of mastery- and performance-oriented instructional practices, we found that the instruction type $\times$ orientation interaction was significant for teachers' ability-approach, ability-avoidance, mastery, and work-avoidance orientations, $F \mathrm{~s}>6.54$, ps $<$ $.012, \eta_{\mathrm{ps}}^{2}>.026$, and marginally significant for their relational orientations $F(1,240)=2.98, p=$ $.086, \eta_{\mathrm{p}}^{2}=.012$ 
This effect was moderated by domain in the case of work avoidance orientations ( $p=$ .017), but not for any of the other orientations. Exploration of these interactions revealed that mastery-oriented instructional practices were positively correlated with teachers' mastery, $F(1$, $240)=31.87, p<.001, \eta_{\mathrm{p}}^{2}=.117$, and relational orientations, $F(1,240)=6.74, p=.010, \eta_{\mathrm{p}}^{2}=$ .027 , and negatively correlated with their ability avoidance, $F(1,240)=4.95, p=.027, \eta_{\mathrm{p}}^{2}=$ .020 , and work avoidance orientations, $F(1,240)=2.75, p=.098, \eta^{2} \mathrm{p}=.011$ (though this last effect was only marginal). Conversely, performance-oriented practices were positively correlated with their ability-approach, $F(1,240)=13.42, p<.001, \eta^{2} \mathrm{p}=.053$, ability-avoidance, $F(1,240)=25.04, p<.001, \eta^{2}=.094$, and work-avoidance orientations, $F(1,240)=9.58, p=$ $.002, \eta_{\mathrm{p}}^{2}=.038$, and negatively correlated with their mastery orientations, $F(1,240)=7.12, p=$ $.008, \eta^{2} \mathrm{p}=.029$

With respect to whether teachers' goal orientations predict their differential treatment of low and high ability students, we found that the ability level $\times$ instruction type $\times$ orientation interaction was significant for ability-approach orientations, $F(1,240)=5.96, p=.015, \eta^{2} \mathrm{p}=$ .024 , and marginally significant for mastery orientations, $F(1,240)=2.86, p=.092, \eta_{\mathrm{p}}^{2}=.012$. Neither of these effects were moderated by domain ( $p$ s $>.410)$. Also, note that the effect of ability-approach orientations remained significant when including mindset familiarity and special education focus as covariates.

Follow-up analyses showed that the stronger teachers' ability-approach orientations were, the marginally more they engaged in differential treatment with respect to both mastery-oriented practices, $F(1,240)=3.19, p=.075, \eta_{\mathrm{p}}^{2}=.013$, and performance-oriented practices, $F(1,240)=$ $4.00, p=.047, \eta^{2} \mathrm{p}=.016$. And, the stronger teachers' mastery orientations, the marginally less they engaged in differential treatment with respect to mastery-oriented practices, $F(1,240)=$ 
$3.33, p=.069, \eta^{2}{ }_{p}=.014$, but not performance-oriented practices, $F(1,240)=.68, p=.410, \eta^{2}=$ .003 .

\section{Teachers' goal orientations as mediating the effects of general mindsets on self-} reported instructional practices. Because teachers' ability-approach, ability-avoidance, and mastery orientations were significantly correlated with their general academic mindsets and significantly associated with their use of mastery- vs. performance-oriented instructional practices (see the mindset $\times$ instruction type interactions above), we examined whether these orientations might mediate the effects of mindsets on their use of different instructional practices. To do this, we first subtracted teachers' ratings of performance-oriented instructional practices (collapsed across the high and low ability scenarios) from their ratings of mastery-oriented practices, such that higher numbers indicated greater use of mastery practices relative to performance practices. The association between the resulting score and the mindset measure is roughly equivalent to the instruction type $\times$ mindset interaction from previous analyses (but without accounting for Domain). Next, we conducted a bootstrapping mediation analysis (Hayes, 2013) with 5,000 resamples in which general mindset was the independent variable, abilityapproach, ability-avoidance, and mastery orientations were the mediators, and instructional practices was the outcome. The results showed that the $95 \%$ confidence interval for the total indirect effect excluded zero, $b=.10,95 \% \mathrm{CI}[.05, .17]$, suggesting that, together, abilityapproach, ability-avoidance, and mastery orientations significantly mediated the effect of mindsets on instructional practices. Individually, ability-avoidance $b=.05,95 \%$ CI $[.02, .11]$ and mastery orientations $b=.04,95 \%$ CI [.01, .09] were significant mediators, but ability-approach orientation was not $b=.003,95 \%$ CI [-.02, .03]. In addition, the direct effect of mindsets on instructional practices was significant, $b=.21, \mathrm{p}<.001$, which suggests that there are other factors mediating the relation between these variables, in addition to teachers' goal orientations. 
Because teachers' ability-approach and mastery orientations (but not ability-avoidance orientations) were also correlated with their differential treatment of high and low ability students, we decided to test the possibility that these orientations mediated the effects of mindsets on differential treatment. To do this, we first computed a measure of differential treatment using the following formula: (mastery practices for high ability students - mastery practices for low ability students) - (performance practices for high ability students performance practices for low ability students). The association between the resulting score and the mindset measure is roughly equivalent to the ability level $\times$ instruction type $\times$ mindset interaction from previous analyses. Next, we conducted a bootstrapping mediation analysis (Hayes, 2013) with 5,000 resamples in which general mindset was the independent variable, ability-approach and mastery orientations were the mediators, and differential treatment was the outcome. The results showed that the $95 \%$ confidence interval for the total indirect effect excluded zero $b=-.03,95 \%$ CI [-.09, -.001], suggesting that, together, ability-approach and mastery orientations significantly mediated the effect of mindsets on instructional practices. Individually, ability-approach orientation was a significant mediator $b=-.02,95 \%$ CI [-.06, $.001]$, but mastery orientation was not $b=-.01,95 \%$ CI $[-.05, .009]$. In addition, the direct effect of mindsets on differential treatment was significant $b=-.13, p=.042$, which suggests that there are other factors mediating the relation between these variables, in addition to teachers' goal orientations. For additional mediation analyses that were conducted, contact the first author.

To summarize, these findings support the idea that teacher goals may play a small, but important role in explaining the association between teacher mindsets and differential treatment. However, these findings are very preliminary and do not necessarily rule out the presence of other meditational pathways, including those discussed in the General Discussion and throughout these supplementary materials. Future studies should more directly assess potential mediators in 
order to better account for why teachers' growth mindsets are associated with their differential treatment of low and high ability students.

\section{Additional Studies Conducted}

After conducting the two studies reported in this manuscript, we conducted another with college students in which ability level was manipulated between participants. That is, the participants were asked to imagine working with a single above average or below average fifth grade math student, but not both. The purpose of the study was to develop a more comprehensive and reliable measure of teachers' instructional practices. Thus, participants were asked to rate how likely they would be to use over 70 different practices on a 0 to $100 \%$ scale.

Although preliminary analyses showed that participants' field-specific growth mindsets (but not their general mindsets) predicted their use of performance- and mastery-oriented instructional practices in opposite directions (i.e., the mindset $\times$ instruction type interaction was significant, $p<.05$ ), we did not find that this pattern varied based on the perceived ability level of the child. This could have been partly due to the fact that we used a different measure of instructional practices or to a lack of power, but it could also have been because the participants did not rate practices for multiple student (i.e., they were not primed to engage in social comparison processes; see the previous section on order effects, pp. S13-14). Note that we have also conducted a study examining whether participants differential treatment varies by mindset and by the race of the hypothetical students. Data from this study have not yet been analyzed.

Finally, we have collected data from over 100 elementary school teachers from two different locations in Russia. The dataset includes abbreviated measures of teachers' general, domain/child-specific, and field-specific growth mindsets, as well as a questionnaire-based measure of their strategies for working with low math ability students. Prior to translation, the four items from the differential treatment measure were: 
1. Encouraging students with low math ability to learn complex math concepts is not an effective teaching strategy.

2. For students with low math ability, teachers should focus only on developing their basic math skills.

3. Teaching students with low math ability several strategies for solving one type of math problem will probably confuse them.

4. Giving students a choice of how to solve a math problem might be an effective strategy when working with the students with high math ability, but not the students with low math ability.

We found that that teachers' with weaker general growth mindsets were significantly more likely to endorse these items than those with stronger growth mindsets, $p<.001$. Teachers'

domain/child-specific and field-specific mindsets (including their verbal/humanities-specific mindsets) were also significantly associated with their endorsement of these math-specific strategy items (though these correlations varied a bit by location). This provides further support for our hypothesis that teachers' growth mindsets predict their treatment of low-ability students. 


\section{References}

Butler, R. (2012). Striving to connect: Extending an achievement goal approach to teacher motivation to include relational goals for teaching. Journal of Educational Psychology, 104(3), 726-742.

Chalmers, R. P. (2018). On misconceptions and the limited usefulness of ordinal alpha. Educational and Psychological Measurement, 78(6), 1056-1071.

Crutzen, R., \& Peters, G. J. Y. (2017). Scale quality: alpha is an inadequate estimate and factoranalytic evidence is needed first of all. Health Psychology Review, 11(3), 242-247.

Dunn, T. J., Baguley, T., \& Brunsden, V. (2014). From alpha to omega: A practical solution to the pervasive problem of internal consistency estimation. British Journal of Psychology, 105(3), 399-412.

Gadermann, A. M., Guhn, M., \& Zumbo, B. D. (2012). Estimating ordinal reliability for Likerttype and ordinal item response data: A conceptual, empirical, and practical guide. Practical Assessment, Research \& Evaluation, 17(3), 1-13.

Garrido, L. E., Abad, F. J., \& Ponsoda, V. (2013). A new look at Horn's parallel analysis with ordinal variables. Psychological methods, 18(4), 454-474.

Garrido, L. E., Barrada, J. R., Aguasvivas, J. A., Martínez-Molina, A., Arias, V. B., Golino, H. F., ... \& Rojo-Moreno, L. (in press). Is small still beautiful for the strengths and difficulties questionnaire? Novel findings using exploratory structural equation modeling. Assessment.

Green, S. B., \& Yang, Y. (2009). Commentary on coefficient alpha: A cautionary tale. Psychometrika, 74(1), 121-135. 
Haimovitz, K., Wormington, S. V., \& Corpus, J. H. (2011). Dangerous mindsets: How beliefs about intelligence predict motivational change. Learning and Individual Differences, 21, $747-752$.

Hancock, G. R., \& Mueller, R. O. (2011). The reliability paradox in assessing structural relations within covariance structure models. Educational and Psychological Measurement, 71, 306-324.

Hayes, A. F. (2013). Introduction to mediation, moderation, and conditional process analysis. New York: The Guilford Press.

Horn, J. L. (1965). A rationale and test for the number of factors in factor analysis. Psychometrika, 30(2), 179-185.

Hu, L. T., \& Bentler, P. M. (1999). Cutoff criteria for fit indexes in covariance structure analysis: Conventional criteria versus new alternatives. Structural equation modeling: $a$ multidisciplinary journal, 6(1), 1-55.

Jonsson, A. C., Beach, D., Korp, H., \& Erlandson, P. (2012). Teachers' implicit theories of intelligence: Influences from different disciplines and scientific theories. European Journal of Teacher Education, 35(4), 387-400.

Kang, Y., McNeish, D. M., \& Hancock, G. R. (2016). The role of measurement quality on practical guidelines for assessing measurement and structural invariance. Educational and psychological measurement, 76(4), 533-561.

Kelley, K., \& Pornprasertmanit, S. (2016). Confidence intervals for population reliability coefficients: Evaluation of methods, recommendations, and software for composite measures. Psychological Methods, 21(1), 69-92.

Kenny, D. A., Kaniskan, B., \& McCoach, D. B. (2015). The performance of RMSEA in models with small degrees of freedom. Sociological Methods \& Research, 44(3), 486-507. 
Leslie, S. J., Cimpian, A., Meyer, M., \& Freeland, E. (2015). Expectations of brilliance underlie gender distributions across academic disciplines. Science, 347(6219), 262-265.

McNeish, D. (2018). Thanks coefficient alpha, we'll take it from here. Psychological Methods, $23(3), 412-433$.

McNeish, D., An, J., \& Hancock, G. R. (2018). The thorny relation between measurement quality and fit index cutoffs in latent variable models. Journal of personality assessment, 100(1), 43-52.

Mueller, C. M., \& Dweck, C. S. (1998). Praise for intelligence can undermine children's motivation and performance. Journal of personality and social psychology, 75(1), 33-52.

Muenks, K., Miele, D. B., Ramani, G. B., Stapleton, L. M., \& Rowe, M. L. (2015). Parental beliefs about the fixedness of ability. Journal of Applied Developmental Psychology, 41, $78-89$.

Patterson, M., Kravchenko, N., Chen-Bouck, L., \& Kelley, J. (2016). General and domainspecific beliefs about intelligence, ability, and effort among preservice and practicing teachers. Teaching and Teacher Education, 59, 180-190.

Revelle, W. (2017) psych: Procedures for Personality and Psychological Research, Northwestern University, Evanston, Illinois, USA, https://CRAN.R-project.org/package=psych Version $=1.7 .5$.

Stipek, D. J., \& Gralinski, J. H. (1996). Children's beliefs about intelligence and school performance. Journal of Educational Psychology, 88, 397-407.

Yang, Y., \& Green, S. B. (2011). Coefficient alpha: A reliability coefficient for the 21 st century?. Journal of Psychoeducational Assessment, 29(4), 377-392. 